\title{
Financial Stability in Kenya. Does Inclusive Finance Matter?
}

\author{
Antony R Atellu* Peter W Muriu Odhiambo Sule \\ School of Economics, University of Nairobi, Kenya
}

\begin{abstract}
Kenya has made significant stride in financial inclusion compared to other Sub-Saharan economies. Using time series data for the period 2004 to 2017 and Structural Equation Modelling (SEM), this study seeks to investigate whether there are trade-offs or synergies between inclusive finance and financial stability. Previous evidence suggests both positive and negative effects, but evidence on emerging economies such as Kenya is clearly lacking. This can partly be attributed to scarcity of data on inclusive finance. Estimation results reveal that access and usage of financial services may foster financial stability in Kenya. Therefore, policies that enhance access and usage of financial services may boost financial stability.
\end{abstract}

Keywords: Financial Inclusion, Structural Equation Model, Financial Stability

JEL classification: G21, G28, O16.

DOI: $10.7176 / \mathrm{JESD} / 10-6-07$

Publication date:March $31^{\text {st }} 2019$

\section{Introduction}

Financial inclusion is a multidimensional aspect that involves three most important basic elements that include access, usage and quality of financial services (Roa, 2015). Though the financial system in Kenya has grown fast in the last fifteen years, access to financial services is still skewed towards the large private and public enterprises in urban areas. According to FinAccess survey (2015) distribution of bank branches in urban and rural areas stood at approximately 95 per cent compared to arid and semi- arid which stood at only $21 \%$ (Financial Sector Deepening Kenya, 2015). Financial Sector Deepening Kenya (FSDK) (2016) shows that uptake of financial services has significantly improved in Kenya. This is attributed to the use of new mobile banking services such as M-Shwari and KCB M-PESA with 18 per cent of the population utilizing these services. Thus, the proportion of bank account users has risen to 38 per cent, signifying a 10 per cent increase from 2013. Despite this improvement, the data confirms that there is still room for improving financial inclusion.

Financial stability is still a key priority among policy makers across the globe. For example, the G-20 in 2009 established Financial Stability Board (FSB) to monitor and make regulatory recommendations on global financial system. Ahamed and Mallick (2017a) shows that banks that utilize regulatory forbearance on the rationalized commercial loans significantly improve their stability by reducing risk taking ventures owing to a business provisioning enjoyed by banks that own those assets. Assessment of financial risk has shifted from the risk of default by an individual financial institution to a wider system assessment of financial markets, institutions and infrastructure (Financial Stability Report, 2011). Furthermore, the focus has been on institutions that are too big to fail, intricacy and systematic network, which would cause a major interruption to the larger financial system and economic activities.

The main objective of this paper is to investigate the effect of financial inclusion on financial stability in Kenya. Specifically, we examine if there are trade-offs between financial inclusion and stability. Secondly, we seek to establish whether there are synergies between financial inclusion and stability. Financial sector development is one of the pre-requisites of economic growth as highlighted in Kenya's vision 2030. Reforms to promote financial development (financial invention, innovation, inclusion and competition) started in 2007 with introduction of mobile money services and later agency banking in 2011 among other financial sector reforms. Kenya is the most financially inclusive country in Africa with over $70 \%$ of the population being included in the financial system (Makina, 2017). Despite this growth, the financial system has been exposed to occasional systemic risks that have led to volatility of the financial sector since 2014. For instance, the level of credit risks as proxied by gross Non-Performing Loans (NPL) rose to $65.1 \%$ in March 2017 up from 57.2\% in March 2016. Further, the ratio of gross NPLs to gross loans significantly increased from $6.8 \%$ in 2016 to $12.3 \%$ in 2017 (CBK, 2017).

The banking sector was also exposed to liquidity risks combined with distorted distribution that led to two banks being placed under receivership and another bank being liquidated, for the first time in over a decade. Four merges were actualized in 2016 compared to only three that were announced between 2002 and 2015. Credit advanced to private sector also reduced from 5.5\% in 2016 to 3.5\% in December 2017 (CBK, 2017). Considering the increase in the level of financial inclusion (see FSDK, 2016), the research question that remains unresolved is why inclusive finance has not translated into a stable and resilient financial system.

Financial stability is one of the major policy objectives in many countries including Kenya. However, this objective is considerably difficult to define, and measure compared to other traditional policy objectives like 
macroeconomic and price stability (Hannig and Jansen, 2010). Stability of the financial sector relies on the interdependence of crucial elements of the financial system. However, this does not rule out occasional failures of small and medium enterprises (SMEs) and large business initiatives, which constitutes normal running of the financial system (Crockett, 2002). Financial inclusion alters the structure of the financial system in terms of access, usage, innovations, new risks and the introduction of new institutions in the already existing market. Evidence so far points to trade-offs (Khan, 2011; Cihak et al., 2016) and synergies (Prasad, 2010; Hannig and Jansen, 2010; Aduda and Kalunda, 2012; Han, 2013; Morgan and Pontines, 2014) between financial inclusion and financial stability.

Financial sectors with high levels of inclusivity are able to diversify investments and stabilize deposit base thus reducing the dependence of non-core financing which influences systemic stability. Second, inclusive finance leads to diversification of loan portfolios by financial institutions to small-scale borrowers which mitigating systemic risks over time. Third, when majority of the population is included in the financial system monetary policy transmission would be more effective in achieving its objective of a robust financial system (Khan, 2011, Mehrotra and Yetman, 2015). In terms of tension, financial inclusion through increased credit growth may lead to an increase in NPLs, which would threaten stability of the financial sector. Furthermore, reputational risk of commercial banks would be threatened if they focus on low-income borrowers by subcontracting roles like credit assessment.

It is not clear whether there are trade-offs or synergies between inclusive finance and financial stability in Kenya. There is limited empirical work that links financial inclusion and financial stability with most studies focusing on the impact of financial development on inequality; growth and reduction of poverty (see Kibua, 2007; Gichuhi, 2013). Studies that focus on financial inclusion and financial stability in Kenya are exploratory in nature (see e.g. Aduda and Kalunda, 2012; Mwega, 2014; Amanja, 2015). Further, literature on inclusive finance and growth tends to ignore the connection between financial inclusion and financial stability. Consistent with this research problem, this study seeks to address two questions. At what point should policy makers strike a balance between these two policy objectives? What are the coactions between financial inclusion and financial stability? This study is exceptional because we select proxies of the two latent variables viz. financial inclusion and financial stability and use structural equation model (SEM) to establish the causality between the two variables. There are several advantages in using SEM for our analysis. For example, when variables cannot be measured directly, it corrects for measurement errors and evaluates the variance and covariance of a model. Further, it assists in establishing causal relationships in multivariate multiple regressions. One can also estimate a non-recursive model using SEM.

This paper makes at least three main contributions to an emerging literature on financial inclusion. First, it is timely in view of the broader policy issue on examining which variables of inclusive finance are important in mobilizing the unbanked population into the banking system. Second, previous literature has largely ignored the effect of inclusive finance on financial stability in Kenya. Therefore, this study contributes to financial intermediation hypothesis, which emphasizes on the importance of deposit mobilization to ensure stability and development of the financial system. Finally, our study breaks new grounds by using SEM estimation technique, in studying the effect of financial inclusion on stability of the financial system in Kenya. This will enable us tackle the problem of approximating measurement errors, using both latent constructs and indicator constructs and allowing covariance between different latent constructs to explain the nexus between inclusive finance and financial stability.

\section{Previous Evidence}

Studies on the link between financial inclusion and financial stability are limited and at the same time contradictory. The need for access to financial services is emphasized in existing theory as a policy instrument to promote financial stability (Allen, 1990). Hawkins (2006) documents how advancing access to financial services improves financial stability both in the long run and short run using selected Sub-Saharan African countries. The author uses number of ATMs per 1,000 square kilometers (Geographical branch) and number of ATMs per 100,000 people (demographic branch) as proxy for Access. She suggests that to increase access and stability concurrently there should be communication of the objective of such policies to allow effective implementation, enhanced regulatory and supervisory capacity that supports tiered banking system and prioritization of policies. Consequently, Han and Melecky (2013) used data from 95 countries in the world to investigate the relationship between wider access to bank deposits before 2008 crisis, changes in bank deposit growth during the crisis and how resilient bank deposits funding react during a financial crisis. Growth of bank deposits (percentage of individuals who saved in the past years) is used as a proxy for Access and the Z-score and liquid assets to deposit ratio is used to measure stability of the financial system. Empirically the paper tries to link financial inclusion (bank deposits) with financial (banking sector) stability and resilience. Using robust standard errors and general methods of moment's regression (GMM), they found out that wider use of bank deposits would tremendously reduce deposit withdrawals in times of a financial crisis. This finding is consistent with Cull et al. (2014) and Prasad (2010). 
However, it should be noted that this effect is not predominantly robust in crisis countries because estimation between the interaction of deposit utilization and banking crisis dummy variable proved to be statistically insignificant. Sarma and Pais (2011) in their study of 49 developing countries assert that as financial inclusion expands stability of the banking system improves as reflected by reduction in non-performing asset. A multidimensional index of financial inclusion that included access (number of bank accounts per 1,000 population), availability (bank branches and ATMs per 10,000 population) and usage (volume of credit plus deposit relative to GDP) was used to explain stability in the banking system which in turn ensured financial system stability. To reinforce this argument, Hannig sand Jansen (2010), posit that during business cycle, low-income individuals rarely change their financial behavior. Therefore, during a financial crisis banks depend on low-income savers to continue providing funds when they do not have funds or when they cannot roll over their loans. Financial institutions can therefore shield themselves against changes in interest rates and volatile market conditions by having a more diversified and steady funding base. This can be achieved by concentrating on low-income saver to mobilize deposits (Khan, 2011; Hannig, 2010; Demetriades and Siong, 2006).

Prasad (2010) further demonstrates that financial inclusion in terms of increased domestic savings and lending will encourage domestic investments compelling countries to reduce dependence on foreign debts, thus leading to enhanced financial stability. In line with this finding, Adasme et al. (2006), Morgan and Pointes (2014) assert that availing credit to small and medium enterprises (SMEs) would diversify loans leading to a low systematic risk. An improved share of loans to small and medium enterprises (SME) supports financial stability, primarily reducing probability of default by small business entities and reducing non-performing loans. Further, higher per capita GDP tends to improve financial stability (Khan, 2011; Busch, 2017; Ghosh, 2008). Aduda and Kalunda (2014) in their exploratory study also concur with Morgan and Pointes (2014). They suggest that the Government of Kenya should intensify its strategies for inclusive finance. This could be done through financial intermediaries that avail services to low income earners who are consistent in their expenditure and consumption behavior. Their consistency makes them immune to economic cycles. Therefore, including them in the system would ensure stability in deposit and loan bases of financial institutions leading to a stable financial system.

Mehrotra and Yetman (2015) explain the inverse positive relationship between access to better risk management tools and stability of the financial system. When individuals are financially included, they can smoothen their consumption in case of output instability by adjusting on their savings and investment decisions. Consistent with this finding is that of Mehrotra and Yetman (2015). Bachas et al., (2016) in their study of over 300,000 bank accounts in Mexico for beneficiaries of conditional cash transfer, shows that utilization of debit card facilitates monitoring of bank account balances indirectly leading to increased savings and confidence in the financial system.

Contrastingly, a study by Ardic et al., (2013) suggest that although theories that link inclusive finance and financial stability establishes synergies between the two policy variables, empirical evidence still seems to show inconclusive results. The study concludes that when we use deposit account penetration as a proxy for financial inclusion when studying the link between inclusive finance and financial stability the statistical results show neither positive nor negative correlation. The reason for this divergent result as suggested by the author is either due to lack of solid data or indirect relationship between financial inclusion and stability. To reinforce this argument, World Bank's Global Financial Development Report (2012) concludes that: the link between financial inclusion (estimated by number of loan accounts per 1,000 adults) and financial stability (measured by NPLs and risk premium, bank capital/assets) in Low-Income Countries (LIC) and Middle-Income Countries (MIC) is negative and statistically significant. This is because of severe access barriers and higher loan disbursement in markets with banks that are not well capitalized compared to High Income Countries (HIC) with high accessibility and well capitalized banks. We can therefore conclude that financial inclusion may be restrained to the nature of increased financial access. If policy makers concentrate on increasing access to credit then it could increase financial risks, especially when it leads to deterioration in credit quality or tremendous growth in unregulated parts of the financial system.

How regular and frequently a financial service is used also plays a vital role in measuring the level of financial inclusion and stability in an economy. Data on usage is gathered from the users' point of view, which is the demand side of the economy. This makes usage different from access to financial services (Beck et al., 2007). Usage variables determine how households utilize financial services in terms of period and regularity of using the financial product over time. The proxies include but are not limited to average savings balances, borrowers in financial institutions and volume of electronic payments made (Hernandez-Cos and Goofben, 2012)

A study conducted by Zollmann (2014) in Kenya on financial usage covered 300 households evenly distributed in five areas of the country. The study offered an invaluable insight about how Kenyans think and how they use their money. Implications of the study advocated for more diversification of financial services that will assist people to manage short-term liquidity and mitigate against long-term uncertainty in their incomes and consumption needs to ensure stability in the financial sector. Financial service providers are also supposed to customize their products to meet the needs of their customers. This will make customers feel that their savings is 
working for them hence encourage the low-income population to venture into investment opportunities to enhance their livelihoods. Ahmed and Mallick (2017) who analyze the balancing effect of inclusive finance on stability of individual banks using International Monetary Fund Financial Access Survey data for 87 countries in the period 2004-2014 also document consistent findings. They use access to, availability and usage (total volume of deposits and loans relative to GDP) as proxies for inclusive finance. A two-step generalized method of moments (GMM) technique is used to analyze this relationship. The study reveals that advanced access, availability and usage of financial services will lead to bank stability. In the same vein, Amatus and Alireza (2015) investigate the link between access and usage of financial services and stability of the financial sector in Sub-Saharan Africa (SSA) and conclude that outstanding loans from commercial banks have a positive role on financial stability also confirm this evidence. These findings are also in line with that of Lopez and Winkler (2017).

Usage of financial services by the population also leads to bank stability, which indirectly plays a role in ensuring stability of the financial system as a whole. Ahmed and Mallick (2015) in their study of 87 countries in the world investigated the complementary effect of financial inclusion on stability of the banking sector. The study used volume of credit plus deposit relative to the GDP to represent the usage dimension and found a statistically significant relationship between usage and soundness of individual banks. Along the same vein, Swamy (2014) examines the inter-relation and dynamics of bank stability measures in terms of how they determine financial stability and a robust financial market. A significant finding of this study is that liquidity in the banking system is achieved through usage and access of financial services. This in turn improves capital adequacy, quality of assets and profitability leading to a sound banking system and effectively a stable financial system.

On the contrary, Sahay et al., (2015) do not find usage indicator (percentage of adults with accounts who use them to receive government transfers) to be significant in influencing stability of the financial system. Cihak et al (2016) who conclude that usage of financial services also has tensions with financial stability especially when there is widespread irresponsible borrowing by the population arrived at similar inconsistent findings. This may lead to high probability of risky events, unforeseen losses in the financial sector and consequently a financial crisis. To support this counter intuitive argument, Operana (2016) finds that financial inclusion has no impact on financial stability in the Philippines. She argues that expansion of financial inclusion has neither positive nor negative effect on financial stability because there was insufficient evidence to make any conclusive inference. Variables that proxied access (No. of physical institutions) and usage (lending to SMEs) did not show any relationship with indicator of financial stability (NPLs). Perhaps this inconclusive result can be attributed to variables being estimated in terms of access and financial depth. Divergence of these empirical literatures on usage can be attributed to the use of different usage indicators.

Quality of financial services ensures that Products are well customized to client needs and necessary segmentation has been conducted to develop products for all income levels (Triki and Faye, 2013). Further, quality of financial services has gone beyond customization of client needs and incorporated consumer education, protection, adequate infrastructure and regulatory environment that is favorable for innovation and warranting a safe, robust and dependable financial system (Demirguc-Kunt et al., 2017). Literature on how quality of finance affects financial stability at country level is relatively thin. Most studies centre on the two indicators of financial inclusion (access and usage) mostly because of scarcity of data and proxies to measure quality (Cull et al., 2014; Staschen and Gidvani, 2014).

Mismatch between the services that are offered by financial institutions and the demand is a major cause of low uptake of financial services by the population in Africa (Zollmann and Collins, 2010). Upadhyaya (2011) examined segmentation of Kenya's banking sector from 2000 to 2012 . He found out that segmentation led to fragility and inefficiency over time, which led to financial instability (see Beck et al., 2010; Cull et al., 2014).

The opening of Equity bank and Commercial Bank of Africa (CBA) into the financial market and the linking of banking services with mobile phone provider (Safaricom) via M-PESA, has rapidly increased competition in the banking industry. This has in turn improved the reliability and consistency of financial services in Kenya. Currently almost sixteen banks have been linked with mobile phone providers. CBA offers M-Shwari and Equity bank has introduced Equitel Money sim cards to capture the unbanked population in Kenya (FSD, 2015). These combined savings and loan products has benefited majority of the population and their perception towards bank products has significantly improved leading to more individuals opening accounts (Cook and McKay, 2015). These products have led to the integration of payment data into credit files enabling financial institutions assess credit risks and thus lessen their NPLs portfolio. CBA used payment transactions history from Safaricom data to evaluate credit worthiness of its customers and was able to reduce NPLs of its M-Shwari customers (Cook and McKay, 2015). Reduction of NPLs leads to the overall financial sector stability (Demirguc-Kunt et al., 2017).

The ability of customers making sound financial decisions is important in developing a strong personal savings that is important in efficient allocation of resources leading to financial stability. Singh (2017) in his exploratory research of financial literacy and stability in India found out that apart from exposure to fraud and abuse, inadequate education on financial matters might lead to borrowers' behavior that intensifies financial fragility. Literate customers will exercise innovative- enhancing demand on the financial system and improve 
monitoring in the financial market leading to improved transparency and stability in the financial system (Fomum and Jesse, 2017; Hall, 2008; Soskic, 2011). Further, Lukonga (2015) in his study of selected Islamic states in the world emphasizes on the importance of consumer protection to ensure stability of the Islamic financial industry. He asserts that institutional arrangements such as deposit insurance scheme assists in protecting customers from financial losses and leads to financial stability and development (Demirguc-Kunt and Detragiache, 2000; Staschen and Gidvani, 2014; FSD, 2015).

A well-developed financial infrastructure ensures effective operation of financial intermediaries that include credit information bureaus, collateral registries and payment systems and this leads to stability of the financial sector. Financial market infrastructure has grown tremendously overtime in Kenya due to growth of internet, ecommerce, near field communication and mobile phone money transactions (CBK, 2016). Cross border payment in Kenya can now be made in real time just like normal payment allowing most innovative payments firms to compete in retail payments. Banks have widened the range of payment instruments and services, improved cost efficiency and inventive technology enabled financial products and services (CBK, 2016).

These initial findings suggest a divergent outcome on the link between financial inclusion and financial stability. Moreover, studies that have been conducted in terms of how inclusive finance affects stability of the financial system are at cross-country level (see Han and Melecky, 2013; Cihak et al. 2016; Demirguc-Kunt, 2017). Cross-country data has challenges in terms of reliability and quality, country's specific characteristics, the selection process of countries to be compared and issues with the research objective. There are unique country specific characteristics that are not captured. For example, IMF (2016) cited Kenya as a success story in terms of inclusive finance. However, Financial Sector Deepening Kenya (2016) concludes that despite increase in access to financial services, usage, quality, dynamics and welfare of inclusive finance remains a challenge. This study seeks to fill this research gap.

\section{Methodology}

\subsection{Theoretical Framework}

To estimate the link between financial inclusion and financial stability we adopt Diamond and Dybvig (1983) model. They argue that depositors (including firms and households) have random needs for their cash. As a result, individual needs are reflected in the way they withdraw their savings. Since not all depositors can demand for their savings at the same time, banks strive to mobilize deposits from many different sources including households and firms. Reasons being they expect only a small fraction of withdrawals in the short term. Nevertheless, it should be noted that depositors have the right to demand for their deposits anytime they wish to. Banks therefore have the discretion to lend to their customers over a long horizon, while retaining a small amount to cater for the day-today demand by depositors who wish to withdraw. Quantitatively, individual withdrawals are unrelated. Therefore, following the law of large numbers financial intermediaries expect a steady number of withdrawals in a day.

The converse is also true. Since banks lend for longer periods they cannot quickly call in their loans before maturity. Moreover, even if they attempted to call in their loans, it is assumed that borrowers will not be able to refund immediately because they have also invested in long-term ventures. Thus, if all customers decide to demand their funds simultaneously banks will be unable to honor all their demands and it will run out of money before refunding all the customers. Banks will only be able to pay the first customer but will go bankrupt before paying all the customers. This implies that even healthy banks are susceptible to bank runs and bank panics. Diamond and Dybvig assert that each depositor inducement to demand for their deposit depends on what they anticipate other depositors will do. If depositors expect other depositors to rush and withdraw their money then they will be the first to rush to the bank. As a result, this model provides an example of a Nash equilibrium economic game. If depositors genuinely withdraw money for expenditure needs, they all earn interest benefits on the savings that remain but if they all rush to withdraw; they lose interest that they could have earned. They conclude that the only better way to prevent bank runs is to insure deposits and back it by government or central bank. Such insurance compensates depositors incase of a crisis. If depositors are aware of such a scheme they will not rush to withdraw their money even incase of bank run because they will not have a reason to take part in the bank run.

Diamond and Dybvig assume that the most favorable bank deposit contract is based on preferences, technology and information. Consumers get together and form a bank. They each deposit their money in the bank. Depositors' behavior after depositing money is considered a Nash game. The contract has two equilibriums; one of them is a bank run equilibrium, which is worse than the maximum outcome, though it can be mitigated by deposit insurance scheme. It is assumed that the economy has three periods where at period zero individuals deposit money, second period they can decide to withdraw or be patient until the third period. If an individual decides to withdraw in the last period he gets $\mathrm{Y}>1$ which is more than withdrawing in the second period where he gets only 1. Therefore the choice between $(0, Y)$ and $(1,0)$ is made in the second period. Law of Large Numbers (LLN) is assumed in this model, where one individual is small in relation to the whole economy. The model has depositors withdrawing at random depending with their consumption needs or shocks. Let us assume a depositor is impatient and needs to withdraw at period 1 ; then his consumption will be $u\left(C_{1}\right)$ with probability ' $x$ ', and that another 
depositor is patient and withdraws at the second period with probability ' $1-x$ '. His consumption will be $\beta u\left(C_{1}+C_{2}\right)$. The impatient depositor's would be equal to his initial wealth $C_{1}=1$ and his utility will be a unit $u(1)$. A patient depositor will receive $\mathrm{Y}>1$ and his consumption in the second period would be returns multiplied by his initial wealth $C_{2}=Y * 1$. His utility would be $u(Y)$.

We combine all these and use the probability weighted expected utility. Further, we keep in mind that the impatient depositors do not mind about consumption in period two so that it does not affect their expected utility. This can be presented algebraically as follows:

$x u\left(C_{1}^{1}\right)+(1-x) \beta u\left(C_{1}^{2}+C_{2}^{2}\right)$

We now pool all the depositors in the economy and maximize their utility subject to their constraint.

$$
x C_{1}^{1}+(1-x) C_{1}^{2}+(1-x) \frac{1}{y} C_{2}^{2} \leq 1
$$

The first period withdrawal for spending is ineffective if $Y>1$. We first move withdrawals along the available total resource and then we get the best possible utility with full information by forming a Lagrangian equation and solving for the first order conditions to get the marginal utility of both impatient and patient depositors as follows:

$$
x\left(\Delta C_{1}^{1}\right)+(1-x) \frac{1}{y}\left(\Delta C_{2}^{2}\right)=0
$$

Make $\Delta C_{2}^{2}$ to be the subject of the formula in equation (3)

$\Delta C_{2}^{2}=-\frac{x}{1-x} Y \Delta C_{1}^{1}$

The change in expected utility is given by equation (5)

$\Delta E U=x u^{\prime}\left(C_{1}^{1}\right) \Delta C_{1}^{1}+(1-x) \beta u^{\prime}\left(C_{2}^{2}\right) \Delta C_{2}^{2}$

Substitute equation (4) in equation (5) to get equation (6).

$x u^{\prime}\left(C_{1}^{1}\right) \Delta C_{1}^{1}+(1-x) \beta u\left(C_{2}^{2}\right)\left[-\frac{x}{1-x} Y \Delta C_{1}^{1}\right]=0$

Simplify equation (6).

$\left.\left.x\left[w^{(} C_{1}^{1}\right)+\beta w^{(} C_{2}^{2}\right)(-Y)\right] \Delta C_{1}^{1}=0$

Therefore, at optimum present consumption of an impatient depositor is equal to:

$w^{\prime}\left(C_{1}^{1}\right)=\beta Y_{u}\left(C_{2}^{2}\right)$

In addition, $\left(C_{2}^{2}\right)>\left(C_{1}^{1}\right)$ if $\beta Y>1$ as explained by Diamond and Dybvig model.

Suppose there is insurance deposit scheme in the optimal contract then we introduce coefficient of risk aversion: $u(C)=\frac{1}{1-\theta} C^{1-\theta}$

If we get the maximum utility $u^{r}(C)=C^{-\theta}$ where, $\theta$ is coefficient of relative risk aversion. Therefore, if we equate the impatient depositor with the patient depositor with the element of risk aversion we have: $\left(C_{1}^{1}\right)^{-\theta}=Y \beta\left(C_{2}^{2}\right)^{-\theta}$ make $C_{2}^{2}$ the subject, $C_{2}^{2}=C_{1}^{1}(Y \beta)^{\frac{1}{\theta}}$ we then let $(Y \beta)^{\frac{1}{2}}$ be equal to $\mu$ and substitute $C_{2}^{2}=$ $\mu C_{1}^{1}$ and our resource constraint will be:

$x\left(C_{1}^{1}\right)+(1-x) \frac{1}{Y}\left(C_{2}^{2}\right)=1 \Rightarrow C_{1}^{1}=\frac{1}{x+(1-x)^{p} / y}$.

Therefore, when $C_{1}^{1}>1$ then $\mu<Y$ impatient depositor will benefit from withdrawing in period one because utility for consuming now is higher than postponing in future. Thus, substitution effect is lower in period one. Further, if $C_{2}^{2}>C_{1}^{1}$ then $Y \beta>1$ which implies patient depositors will benefit more than the impatient depositors.

Suppose it is difficult to identify the type of depositor until they identify themselves. The banker will constrain the contracts such that depositors will signal their characters voluntary. The impatient depositors would not cheat because the contract will be in such a case that they do not benefit if they cheat. However, tolerant patients may cheat but will not achieve optimal utility. A good contract is incentive compatible if a depositor reports his true character and achieves the highest utility possible. For instance, patient depositor will report his true nature if $u\left(C_{2}^{2}\right)>u\left(C_{1}^{1}\right)$ where $Y \beta>1$. So if depositors are truthful the resources would be allocated optimally, which is not always the case.

We have seen a situation where there is equilibrium outcome on a deposit contract and that all depositors identify themselves with their characters. However, it is plausible that in the event of a bank run and our deposit contract awards every impatient depositor the same amount of $y_{1}$ for every amount that was deposited in the first period. The bank honours all withdrawal and deposit demands randomly depending on a customer's place in the queue and not in future when he is expected to be in the queue. If a depositor is in the queue at point $k$ assuming that customers who arrived early and have withdrawn are a fraction $q_{k}$ but a total portion $q$ of depositors will receive their deposits. Then they will utilize: $y_{1}$ if $y_{1} q_{k}<1$ (the bank is still liquid) and 0 if $y_{1} q_{k}>1$ (bank is insolvent). If depositors do not withdraw, we have, $\max \left(0, Y\left(1-y_{1} q\right) /(1-q)\right)$.

The depositors who liquidate it at period two own the bank. Depositors who did not withdraw in the first period receive a pro rata share of the Bank's property in the second period. Bank run equilibrium will occur when both patient and impatient depositors rush to withdraw their savings in the first period because they expect the value of the liquidated property of the bank to be less than the real cash. Hence, individuals will demand for cash 
deposit until the bank becomes insolvent before it reaches their turn in the queue. If there is insurance deposit, one variant of the contract can eliminate the bad equilibrium. The payoffs for an impatient customer and patient customer will be the same and bank runs will not occur because waiting will be the same as rushing to withdraw. Figure 3.1 demonstrates our theory in a conceptual framework.

Figure 3.1: Conceptual Framework

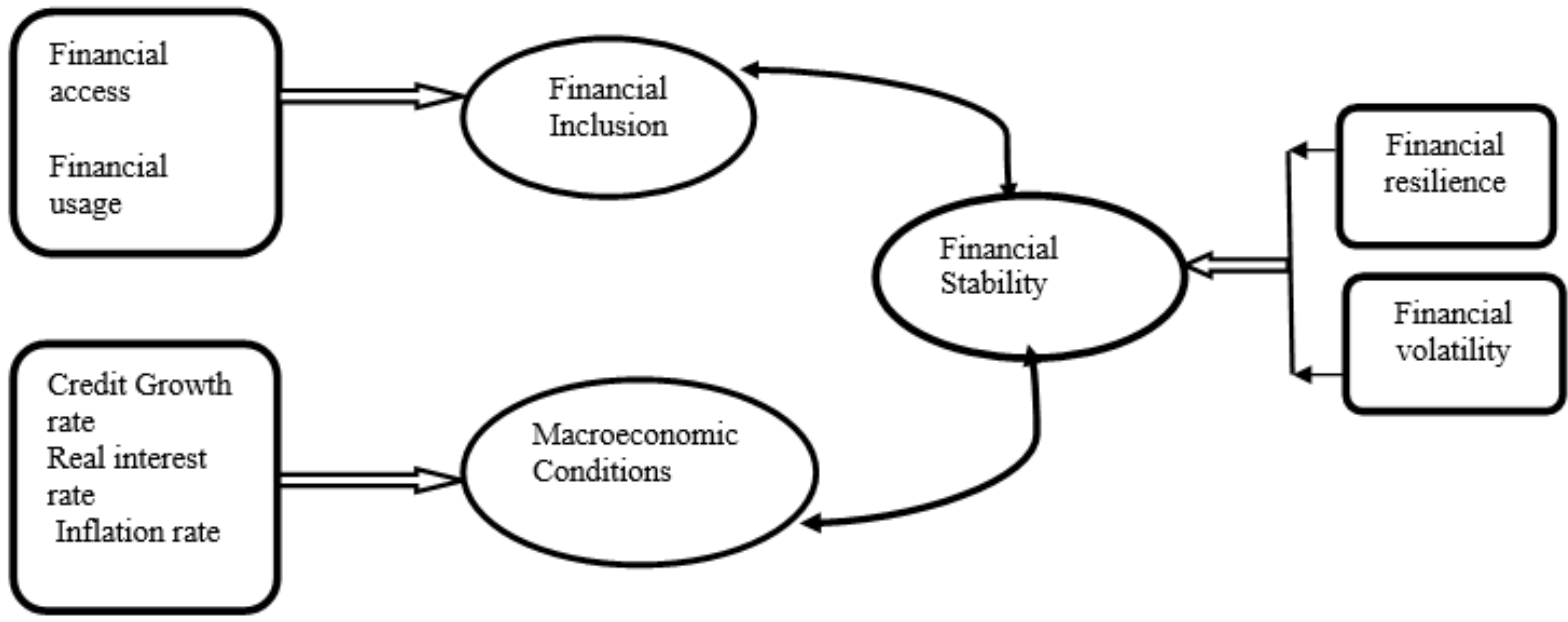

We demonstrate theoretically that if financial intermediaries allow individuals to access and utilize financial services then they would contribute to stability of the financial sector. Financial inclusion through access and usage of financial services would allow banks to mobilize deposits and diversify their investments. This enables banks to forecast, mitigate and absorb systematic shocks in the financial system. Nonetheless, if financial intermediaries invest in high risky ventures and allow high risk customers to access and use financial services they may be vulnerable to liquidity and credit risks that would result into bank runs and financial crisis. We also consider other macro-economic conditions that would affect stability of the financial system (Diamond and Dybvig, 1983). High credit growth rate, inflation and real interest rate may lead to financial crisis. When credit goes to high risky customers and real interest rate keeps on increasing we expect high levels of credit default as risky individuals are unable to pay leading to bank panics and bank runs, as banks may be unable to honor their customers' demands. This would ultimately lead to a financial crisis over time. Further, there is an inverse relationship between increase in the general price level and stability of the financial sector in the long run.

\subsection{Model Specification}

We use structural equation model (SEM) to explain the statistical relationship between variables by examining data and causal assumptions that are qualitative in nature (Pearl, 2000). This empirical method is fundamentally motivated by several reasons. Existing studies on how inclusive finance affects financial stability have used Generalized Methods of Moments (GMM), panel regression and pair wise spearman correlation (see Han and Melecky, 2013; Morgan and Pointes, 2014; World Bank, 2014; Sahay, 2015, Cihak et al., 2016, Amatus and Alireza, 2015). However, these estimation techniques are much applicable to multiple regression and cross-country comparative estimation and have their own limitations. For example, when weak instrument are selected in GMM, they are weakly correlated with endogenous variables leading to misleading inferences (Kiviet, 2009). Consequently, the challenge of panel regression is to control the impact of unobserved heterogeneity, inflating the standard errors, design of the model, data collection challenges and distortion of measurement errors (Yaffee, 2003). Use of Spearman's correlation coefficient is quite complicated, difficult to work out and can easily be misinterpreted (Lehman, 2005). Further, inclusive finance and financial stability are multi dimensional in nature and therefore it would be inaccurate to proxy these constructs using one measurement variable. One is therefore bound to incorporate different measurement variables to proxy latent construct and conduct a multivariate regression analysis using SEM.

We therefore turn to SEM because it is suitable in our case where we have inclusive finance, macroeconomic conditions and financial stability as indicators variables that cannot be estimated directly and have measurement errors. SEM can also be used to confirm our hypothesis that looks at the trade-off and synergy between inclusive finance and financial stability by theoretically developing a model to represent our postulations. SEM would further report the variance, covariance and multiple multilevel regression results of our non-recursive model that looks at inclusive finance and financial stability. Unobservable (latent) variable are explained by directly observable variables and interpreted using hypothetical construct to determine how best it fits the data (RabeHesketh et al., 2004).

Consequently, worldwide fit measurements can offer a quick summary estimation of multifaceted models 
that involve a substantial number of linear equations. Other estimation methods like multiple regressions would give separate mini-tests on model components carried out in equation-to-equation basis (Tomarken and Waller, 2005). SEM allows the use confirmatory factor analysis to obtain measurement variables that effectively proxy the latent constructs which comprises of inclusive finance, macroeconomic conditions and financial stability to ensure better estimation results. We are therefore able to evade having to determine suitable weights, a problem usually experienced when utilizing aggregate estimates or composite variables. Further, SEM helps to solve the identification problem by constraining the mean of exogenous latent construct to zero. Similarly, the intercept of the endogenous latent constructs are also constrained to zero while constraining the coefficient path of the first endogenous measurement indicator variable to have a coefficient of one.

According to Bollen (1989) and Kline (2004), SEM is utilized mostly for exploratory factor analysis and therefore it is divided into two parts: the measurement model (shows the association between a latent variable and measurement variables) and the structural model (shows the relationship between latent variables). Latent variables are defined as variables that cannot be observed directly but are rather explained by observable measured variables. After estimation of parameters in the model, the actual covariance or correlation is compared to an empirical correlation or covariance matrix to ensure consistency. If they are consistent then we consider

The study adapts Bollen (1989) and later Kline (2004) models to estimate how inclusive finance influences financial stability in Kenya. SEM is a combination of both structural and measurement models. Structural model is represented as follows:

$$
\mu=\left[\beta_{1}, \beta_{2}, \ldots, \beta_{n}\right]\left[\begin{array}{c}
\delta_{1} \\
\delta_{2} \\
\vdots \\
\dot{\delta_{n}}
\end{array}\right]+\varepsilon .
$$

Equation (11) shows the relationship between exogenous latent variables $\left(\delta_{1}, \delta_{2}, \ldots, \delta_{n}\right)$, which in our case $\delta_{1}$ signify inclusive finance, and $\delta_{2}$ represents an intervening macroeconomic (control) variables, and endogenous latent variable $\mu$ representing financial stability. $\left[\beta_{1}, \beta_{2} \ldots, \beta_{n}\right]$, proxy the coefficients of the exogenous latent variables. Indicator variables represent each set of latent variables in the model. The inexplicable element of the model is measured by an error term $(\varepsilon)$.

In exogenous quantifiable model, the exogenous latent variable is linked to its indicator variable as follows:

$$
\left[\begin{array}{c}
z_{1} \\
z_{2} \\
z_{3} \\
\cdot \\
\cdot \\
\cdot \\
z_{n}
\end{array}\right]=\left[\begin{array}{ccc}
\gamma_{11} & 0 & 0 \\
1 & 0 & 0 \\
\gamma_{31} & 0 & 0 \\
\vdots & \vdots & \vdots \\
0 & 0 & \gamma_{n}
\end{array}\right]\left[\begin{array}{c}
\delta_{1} \\
\delta_{2} \\
\delta_{3} \\
\vdots \\
\delta_{n}
\end{array}\right]+\left[\begin{array}{c}
\vartheta_{1} \\
\vartheta_{2} \\
\vartheta_{3} \\
\vdots \\
\vartheta_{n}
\end{array}\right]
$$

Where: $z_{1} \ldots z_{n}$ represents the indicator variables for the latent exogenous variables. Inclusive finance is defined by two categories of indicator variables given as financial access and financial usage. Further, another intervening indicator variable included is macroeconomic (control) variables. The regression coefficients of latent exogenous variable are represented by: $\gamma_{11} \ldots \gamma_{n}$ and $\vartheta_{1} \ldots \vartheta_{n}$ denotes the error term. Inclusive finance and macroeconomic conditions represent our exogenous latent variables in the model. Latent variables are not directly observable but are rather inferred from other observable variables. Consequently, in endogenous measurement model, financial stability, which is the endogenous latent variable, is linked by indicator variables as shown below:

$$
\left[\begin{array}{c}
y_{1} \\
y_{2} \\
y_{3} \\
\vdots \\
y_{m}
\end{array}\right]=\left[\begin{array}{c}
\alpha_{1} \\
\alpha_{2} \\
\alpha_{3} \\
\vdots \\
\alpha_{m}
\end{array}\right] \mu+\left[\begin{array}{c}
\epsilon_{1} \\
\epsilon_{2} \\
\epsilon_{3} \\
\vdots \\
\epsilon_{m}
\end{array}\right]
$$

Where $\mathrm{y}_{1} \ldots \mathrm{y}_{\mathrm{m}}$ denotes the indicator proxies for the latent endogenous variables. Indicator variables for financial stability are measured along two dimensions that include financial resilience and volatility. A parsimonious set of variables are chosen to consistently measure financial stability to represent the findings of already existing literature and policy practice. The regression coefficient of the latent endogenous variable are characterized by $\alpha_{1} \ldots \alpha_{\mathrm{m}}$ and $\epsilon_{1} \ldots \epsilon_{\mathrm{m}}$ represents the residual term. The information that is available in the indicator variables' covariance matrices is used to estimate the parameters of the model. This process is followed to confirm that the values of the parameters that will be reported can give an approximation for the models' covariance matrix 
$\sum(\theta), \sum^{\wedge}=\sum \theta^{\wedge}$ that most closely corresponds to the sample covariance matrix of the indicator variables.

The association among the exogenous variables and the endogenous variable is then analyzed after testing the hypotheses about the theoretical relationship between the latent variable and their causes and indicators. The study will then use confirmatory factor analysis (CFA) to test the hypothesized relationship between the indicator variables and the latent constructs.

\subsection{Definition and Measurement of Variables}

Previous studies have used different variables as a proxy of financial stability. For example, Sahay et al., (2015) use bank's Z-score as an indicator of financial stability. However, as theory shows, the definition and measurement of financial stability is not straightforward due to the interconnectedness of different elements within the financial system and the economy (Dattels et al., 2010). It should be noted that regulatory and systematic risks are distinct risks that may lead to a financial crisis. Regulatory risks are associated with changes in regulations that have a negative effect in stability of the system. While system wide risks are risks that emanate from bank panics, fall in prices of assets, financial architecture and behavioural impact of banks. Contagion effects and foreign exchange divergence may also lead to financial instability in the long run. This study shall use variables that measure both regulatory and system wide risks through resilience and volatility of the financial sector to capture the interrelated nature of the system.

Banks' Z-score and ratio of non-performing loans is used to measure financial system resilience. These indicators measure solvency of the financial system over a period of time that are affected by systematic risks. Bank's Z-score is calculated by taking return on asset (ROA) and summing it up with equity to asset ratio then we divide it by the standard deviation of ROA. Z-score is the inverse of the probability of insolvency and it shows the number of standard deviations the ROA must decrease below its predictable value before capital is exhausted and the bank is insolvent (De Nicolo, 2000). A higher value of Z-score therefore portrays a greater banking stability and a lower value indicates instability ( $\mathrm{Li}$ et al., 2017). It is computed from underlying banks unconsolidated data from Bank Scope, which is annual and not seasonal data. Other studies that have used bank's Z-score include (Hesse and Cihak, 2007; Lepetit and Strobel, 2013; Amatus and Alireza, 2015; Morgan and Pointes, 2015; Cihak et al, 2016). The ratio of non-performing loans to total loans is used to measure the exposure of bank's credit to systematic risks in the financial system. As this ratio increases, banks will be vulnerable to potential risks in the financial system that would threaten stability of the financial system (Delis et al., 2014). These last two variables capture regulatory risks of the banking sector.

Volatility is estimated using the standard deviation of deposit growth rate and standard deviation of lending growth rate. The more spread apart the data is, the higher the deviation. Standard deviation is calculated as the square root of variance. We apply the same procedure in deriving the standard deviation of banks' deposit rate. (Mare et al., 2015; Cihak et al., 2016). Our study uses these variables to proxy for financial stability since it captures the two dimensions of stability of the financial sector. Furthermore, using these variables evades the problem of data availability, which is common in estimation.

Financial inclusion is defined by accessibility, usage and quality of financial services. Due to data paucity on measurement of quality over a period, we use the two different indicators of financial inclusion, which include access and usage. We develop proxies of these indicators as established in the existing literature of financial inclusion. Previous studies that have used this data include World Bank (2012), Morgan, Pointes (2015), Ahmed, Mallick (2015), Amatus, Alireza (2015) and Cihak et al., (2016). Financial access is proxied by: Number of deposit account per 100,000 adults, branches of commercial banks per 100.000 adults and Automated Teller Machines per 100,000 adults (Hawkins, 2006; Morgan and Pointes, 2015 Han and Melecky, 2015; Cihak et al., 2016). To measure usage of financial services we use Internet use penetration as percentage of the total population, average growth rate of electronic payment and borrowers from commercial banks per 1000 adults (Amatus and Alireza, 2015; Cihak et al., 2016, World Bank, 2015).

The study also includes intervening control macroeconomic variables that may have an impact on financial stability. Among other exogenous indicators is credit growth to GDP growth rate. A decrease in this ratio will lead to stability of the financial sector because it signifies stability of the economic sector (Hardy and Pazarbasioglu, 1999). Consequently, Real interest rate that is nominal interest rate less actual inflation measures the value of real investment. When real interest rate is high, it means that lenders are benefiting from their investment, which leads to the stability of the financial system because lenders have buffers to protect themselves against any eventuality (Hardy and Pazarbasioglu, 1999; Frankel and Saravelos, 2010). There is an inverse relationship between financial stability and changes in real interest rate.

Inflation also plays a significant role in ensuring stability of the financial system. High inflation rates portray a persistent increase in the general price level. This makes credit products more expensive increasing the probability of defaulting by borrowers and reducing the value of money lent by the banker. This in turn increases the amount of non-performing loans leading to instability in both the financial system and growth of the economy 


\subsection{Econometric approach}

Considering several different indicators that we are going to estimate, we will apply an iterative procedure to check on the general specification of the model and omitted variables problem. The goodness of fit test, robustness of the model and statistical significance of the estimated parameters to be included in the study will be tested. Maximum likelihood estimation (MLE) will be used as our estimation technique to determine the relationship between the latent variables and the indicator variables.

To measure the goodness of fit we adopt the Chi square statistics, Comparative Fit Index (CFI), Tucker Lewis Index (TLI), Root Means Square Error of Approximation (RMSEA) and Standardized Root Mean Square Residual (RMSR). We use this goodness of fit estimates to compare the different model specifications because they offer options for selecting the best model. A model that has a value close to zero in RMSEA indicates a best fit and a robust model that is likely to be superior (Blunch, 2008).

Multivariate normality (assumes that data is normally distributed) and multicollinearity of the model will be assessed. Higher deviation from multivariate normality will lead to overestimation of the statistics hence leading to a type 1 error (Powell and Schafer, 2001). Overestimation of the model may lead to inaccurate measures of goodness of fit and hence biased standard errors. To address the problem of multivariate non-normality we use bootstrapping technique.

When normality assumptions are violated, bootstrapping assists in randomly collecting multiple sub-samples of equal sizes as the original sample and the distribution of these samples can be used to describe the actual population distribution. If association between two independent variables is higher than 0.70 then there is a problem of multicollinearity (Gujarati, 2003). To address the problem of multicollinearity we either drop one or more of the affected variable or combine the variables to form a single variable.

\subsection{Data Sources}

Annual data for the period 2004 to 2017 was used in our analysis. Yearly data on access to financial services indicators (number of deposit accounts per 100,000 adults, number of branches per 100,000 adults and number of ATMs per 100,000) was obtained from the International Monetary fund (IMF), Financial Access Survey data, CBK and FSD Kenya. Usage of financial services indicator (internet use penetration as percentage of the population, average growth rate in volume of electronic payments and borrowers from commercial banks per 1000 adults) was obtained from Internet Live Statistics (ILS), CBK and FAS. Further, yearly data on inflation was obtained from CBK. Data on credit to GDP growth rate was obtained from World Bank's Global Financial Development Database (GFDD) and CBK. Consequently, annual data on real interest rate growth was obtained from World Development Indicators (WDI) and CBK. Data on financial stability indicators proxied by banks' Zscore, ratio of non-performing loans to total loans was obtained from World Bank's GFDD and CBK whereas standard deviation of banks' lending and deposit rate data was obtained from CBK.

\section{Empirical Findings}

Descriptive statistics such as Skewness, Kurtosis, Jarque-Bera (JB) Statistics and Probability Value are calculated for variables of interest. Results of the same are presented in Table 4.1. The highest mean is that of borrowings from commercial banks per 1,000 adults at 101.1 followed by credit growth rate at 24.94, while the lowest mean is that of standard deviation of banks deposit rate growth at 0.37 . Most of the variables are positively skewed except banks Z-score, number of deposit account per 100,000 adults, ATMs per 100,000 adults, real interest rate, credit growth rate and inflation that are negatively skewed. 
Table 4.1: Descriptive Statistics

\begin{tabular}{|c|c|c|c|c|c|c|c|c|c|}
\hline Variables & Notation & Obs & Mean & Std. Dev. & Min & Max & Kurtosis & Skewness & $\operatorname{Pr}(\mathrm{JB}-\mathrm{Stat})$ \\
\hline Banks Z-score & ZSC & 14 & 14.65 & 2.16 & 10.75 & 18.70 & 2.68 & -0.01 & $0.90[0.96]$ \\
\hline Ratio of Non-performing loans & NPL & 14 & 9.97 & 6.59 & 4.70 & 27.50 & 4.71 & 1.70 & $10.12[0.0]$ \\
\hline Standard deviation of banks deposit rate & SBA & 14 & 0.41 & 0.27 & 0.1 & 0.90 & 1.83 & 0.41 & $2.60[0.27]$ \\
\hline Standard deviation of banks' lending rate & SLE & 14 & 0.47 & 0.19 & 0.20 & 0.80 & 1.81 & .070 & $1.96[0.37]$ \\
\hline No. of deposit account per 100,000 adults & NDA & 14 & 4.92 & 1.40 & 2.50 & 6.50 & 1.79 & -0.48 & $3.33[0.19]$ \\
\hline No. of bank branches per 100,000 adults & NBA & 14 & 2.57 & 1.04 & 1.00 & 4.65 & 2.37 & 0.01 & $0.30[0.98]$ \\
\hline ATMs per 100,000 adults & NAA & 14 & 6.57 & 2.79 & 2.50 & 9.90 & 2.14 & -0.65 & $2.27[0.32]$ \\
\hline Internet use penetration ( $\%$ of population) & IUP & 14 & 17.86 & 12.22 & 3.00 & 40.20 & 2.12 & 0.59 & $2.02[0.37]$ \\
\hline Average growth rate in Volume of electronic payment & VEP & 14 & 0.36 & 0.22 & 0.10 & 0.70 & 1.72 & 0.32 & $3.28[0.19]$ \\
\hline Borrowings from commercial banks per 1,000 adults & $\mathrm{BCB}$ & 14 & 101.1 & 35.23 & 20.2 & 272 & 2.08 & 0.09 & $1.36[0.51]$ \\
\hline $\begin{array}{l}\text { Real interest rate } \\
\text { growth }\end{array}$ & RER & 14 & 6.02 & 2.36 & 2.00 & 10.00 & 1.76 & -0.12 & $0.53[0.76]$ \\
\hline Credit growth rate & CGR & 14 & 25.42 & 4.38 & 15.00 & 30.00 & 3.47 & -0.26 & $6.22[0.04]$ \\
\hline Inflation rate & INF & 14 & 7.55 & 2.05 & 5.20 & 12.00 & 2.71 & -1.02 & $4.16[0.12]$ \\
\hline
\end{tabular}

However, most variables have a relatively high peaked distribution as shown by the positive kurtosis in all variables. The highest peaked distributions are evident for ratio of non-performing loans and credit growth rate. Maximum and minimum numbers represents the highest and lowest values respectively. All variables were fairly dispersed from their mean values as shown by their standard deviations. For JB statistics, variables were normally distributed at five percent level of significance except ratio of non-performing loans and credit growth rate. However, at one percent significant level all variables were normally distributed. The probability numbers of adjusted chi-squared distribution is adjusted because small sample distribution values take long to converge under JB test. The data therefore, satisfied the assumption of normality.

Correlation analysis is used to check for collinearity between our variables of interest. We use correlation matrix and variance inflation factor (VIF) to establish whether there is perfect linear relationship among variables. Our main concern though is whether multicollinearity is so pronounced to nullify simultaneous inclusion of the explanatory variables in our regression.

\section{Table 4.2: Correlation Matrix}

\begin{tabular}{|c|c|c|c|c|c|c|c|c|c|c|c|c|c|}
\hline & $\mathrm{NDA}$ & NBA & NAA & IUP & VEP & $\mathrm{BCB}$ & INF & RER & CGR & ZSC & NPL & SBA & SLE \\
\hline NDA & 1.000 & & & & & & & & & & & & \\
\hline NBA & 0.332 & 1.000 & & & & & & & & & & & \\
\hline NAA & 0.411 & 0.409 & 1.000 & & & & & & & & & & \\
\hline IUP & 0.436 & 0.249 & 0.305 & 1.000 & & & & & & & & & \\
\hline VEP & 0.258 & 0.462 & 0.432 & 0.091 & 1.000 & & & & & & & & \\
\hline $\mathrm{BCB}$ & 0.541 & 0.210 & 0.450 & 0.094 & 0.080 & 1.000 & & & & & & & \\
\hline INF & -0.437 & 0.196 & -0.447 & -0.648 & 0.291 & 0.504 & 1.000 & & & & & & \\
\hline RER & 0.136 & -0.448 & 0.199 & 0.228 & 0.422 & -0.456 & -0.325 & 1.000 & & & & & \\
\hline CGR & 0.463 & 0.538 & 0.600 & 0.520 & -0.131 & 0.061 & -0.613 & 0.050 & 1.000 & & & & \\
\hline ZSC & 0.323 & 0.215 & 0.276 & 0.449 & 0.267 & 0.319 & -0.391 & 0.422 & 0.413 & 1.000 & & & \\
\hline NPL & -0.499 & 0.256 & 0.178 & -0.433 & -0.462 & -0.499 & 0.368 & -0.088 & -0.362 & -0.729 & 1.000 & & \\
\hline SBA & 0.366 & -0.308 & 0.352 & 0.238 & -0.194 & -0.002 & -0.447 & -0.004 & 0.303 & 0.199 & -0.232 & 1.000 & \\
\hline SLE & 0.587 & -0.175 & 0.446 & -0.408 & -0.193 & 0.024 & -0.549 & -0.074 & 0.413 & 0.186 & -0.337 & 0.406 & 1.000 \\
\hline
\end{tabular}

Multicollinearity is contentious when the score is higher than 0.70 (Gujarati, 2003) to warrant a reduction in 
the t-statistics. This may lead to inestimable standard errors and undetermined parameter estimate. Further, the researcher may accept the null hypothesis which otherwise was supposed to be rejected leading to a Type-2 error. Gujarati (2003) asserted that the cut-off of multicollinearlity is 0.70 as the border of "extreme". Our matrix of implied correlation among variables of interest in Table 4.2 suggests there is a relatively low correlation among variables of interest.

We further use VIF to establish the possible degree of multicollinearlity among our variables. According to the rule of thumb, variables that have a VIF higher than 10 and a tolerance value expressed as 1/VIF higher than 0.1 may warrant further investigation. Table 4.3 shows our VIF results and the tolerance value of our variables. The VIF and tolerance value of our measurement variables show there is no multicollinearlity among these variables. The mean VIF is at 6.45 , which is below the expected threshold of 10 . We can therefore conclude that our variables are suitable for estimating our model.

Table 4.3: Variance Inflation Factor (VIF)

\begin{tabular}{|l|l|l|}
\hline Variable & VIF & $1 /$ VIF \\
\hline NDA & 6.67 & 0.16 \\
\hline NBA & 4.30 & 0.23 \\
\hline NAA & 3.94 & 0.25 \\
\hline IUP & 7.81 & 0.13 \\
\hline VEP & 8.09 & 0.12 \\
\hline BCB & 7.86 & 0.13 \\
\hline INF & 5.08 & 0.20 \\
\hline RER & 9.01 & 0.09 \\
\hline CGR & 6.03 & 0.17 \\
\hline ZSC & 4.30 & 0.23 \\
\hline NPL & 7.58 & 0.14 \\
\hline SBA & 8.23 & 0.11 \\
\hline SLE & 4.65 & 0.21 \\
\hline Mean VIF & 6.45 & \\
\hline
\end{tabular}

\subsection{Exploratory Factor Analysis}

Exploratory factor analysis is utilized in identifying the most efficient factors that express maximum information in our model (Henson and Roberts, 2006). We perform a factor analysis and create a communality table, which expresses to what extent the extracted factors elucidate the variability in the observed measurement variables together with their Eigen values and the percentage of variation that each factor explicates. The first and second steps will assist us in determining how many factors to use in our analysis. We start by extracting a table of factor analysis and selecting factors with Eigen values greater than one in line with the KMO rule. Table 4.4 shows the factor loadings, corresponding Eigen values and variability of these factors. We choose three factors with Eigen values greater than one and explaining $85 \%$ of the variation in the data. The first factor explains $56 \%$ of the variation; the second factor explains $19 \%$ of the variation while the third factor explains $10 \%$ of the variation.

Table 4.4: Factor Loadings

\begin{tabular}{|c|c|c|c|}
\hline Factor & Eigen value & Proportion & Cumulative \\
\hline 1 & 3.39 & 0.56 & 0.56 \\
\hline 2 & 2.38 & 0.19 & 0.75 \\
\hline 3 & 1.29 & 0.10 & 0.85 \\
\hline 4 & 0.92 & 0.06 & 0.91 \\
\hline 5 & 0.64 & 0.03 & 0.92 \\
\hline 6 & 0.53 & 0.04 & 0.97 \\
\hline 7 & 0.31 & 0.02 & 0.99 \\
\hline 8 & 0.11 & 0.01 & 1.00 \\
\hline 9 & 0.04 & 0.00 & 1.00 \\
\hline 10 & 0.02 & 0.00 & 1.00 \\
\hline 11 & -0.01 & 0.00 & 1.00 \\
\hline 12 & -0.00 & 0.00 & 1.00 \\
\hline 13 & -0.00 & -0.00 & 1.00 \\
\hline
\end{tabular}

Further, the choice of factors is reinforced by the construction of a scree plot in figure 4.1. The scree plot shows that only three factors have Eigen values above one. We will therefore extract the three factors that have a significant effect in our data. 
Figure 4.1: Scree Plot of Eigen Values

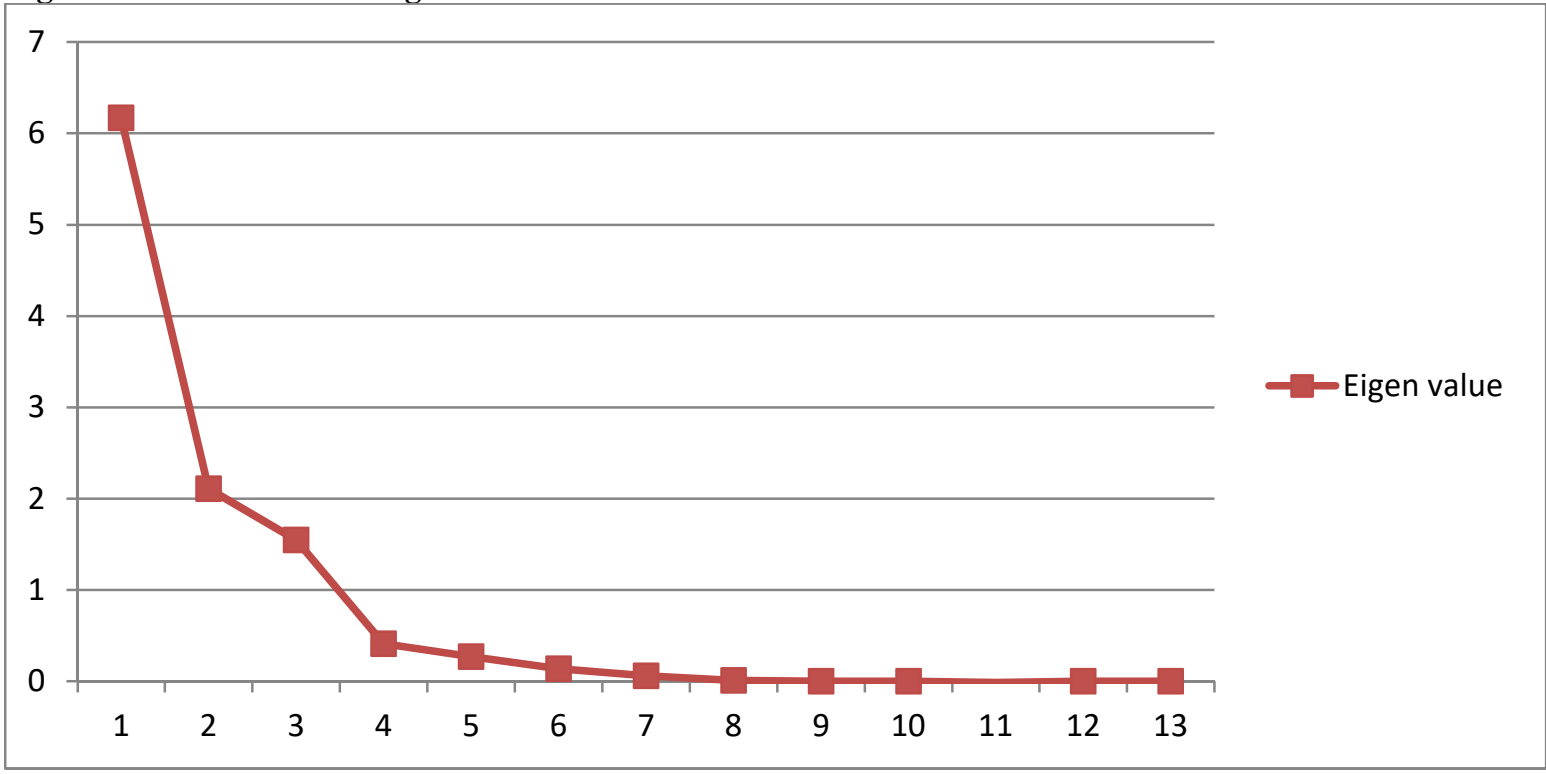

We choose the three factors and perform a factor rotation to determine the factor loadings of the different original measurement variables. Factor rotation shows the correlation between the factors and the original measurement variables. Very high correlations shows that a given original measurement variable loads highly on a given factor. Table 4.5 shows the outcome of varimax rotation (orthogonal matrix rotation to align with coordinates) and how the original measurement variables load on factor one (inclusive finance), factor two (financial stability) and factor three (macro economic conditions). Uniqueness is the error term of the original measurement variables that is not explained by the common factors. Uniqueness is inversely related to communality in that communality is what is explained by the common factors (communality $=1-$ uniqueness). The highest unique value in our data is that of internet use penetration as percentage of the population (IUP) which shows that $29 \%$ of the residual is not explained by this factor.

Table 4.5: Factor Rotation Matrix using Varimax

\begin{tabular}{|c|c|c|c|c|}
\hline Variable & Factor 1 & Factor 2 & Factor 3 & Uniqueness \\
\hline NDA & 0.87 & & & 0.11 \\
\hline NBA & 0.75 & & & 0.03 \\
\hline NAA & 0.92 & & & 0.10 \\
\hline IUP & 0.80 & & & 0.29 \\
\hline VEP & 0.81 & & & 0.10 \\
\hline $\mathrm{BCB}$ & 0.78 & & & 0.20 \\
\hline INF & & & -0.76 & 0.17 \\
\hline RER & & & 0.92 & 0.09 \\
\hline CGW & & & 0.96 & 0.03 \\
\hline ZSC & & 0.88 & & 0.07 \\
\hline NPL & & -0.96 & & 0.08 \\
\hline SBA & & 0.91 & & 0.15 \\
\hline SLE & & 0.95 & & 0.03 \\
\hline
\end{tabular}

Blanks represent observation loadings less than 0.3.

\subsection{Reliability and Adequacy Test}

To test for reliability in factor analysis we use Cronbach's Alpha reliability test (CA) which calculates the internal consistency of summative rating scale comprising of the items stated in the data. The total number of individual item score is referred to as the scale and they can be constructed using raw item scores or sometimes standardized scores. The square root of reliability outcome $(\alpha)$ is the measurement of correlation of a test with true scores that contain minimal errors (Nunnally and Bernstein, 1994). A value above 0.7 of CA shows that the data is reliable when performing a confirmatory factor analysis (see Nunnally and Bernstein, 1994). Table 4.6 shows the outcome of our reliability test. Scale derived from our chosen variables in the data appears to be statistically meaningful since the measured correlation between the scale reliability coefficient and the basic factor it measures $(\sqrt{0.89})$ is approximately 0.94 . The reliability and scale of the variables is based on total standardized variables. The average interim correlation is 0.38 with a corresponding alpha coefficient of 0.89 comprising of all items. All the included 
variables seem to fit well in the scale as shown by the item-test and item-rest correlations.

Table 4.6: Cronbach's Alpha Reliability Test

\begin{tabular}{|l|l|c|c|c|c|c|}
\hline Item & Obs & Sign & $\begin{array}{l}\text { Item-test } \\
\text { correlation }\end{array}$ & $\begin{array}{l}\text { Item-rest } \\
\text { correlation }\end{array}$ & $\begin{array}{l}\text { Average Interim } \\
\text { correlation }\end{array}$ & Alpha \\
\hline NDA & 14 & + & 0.93 & 0.91 & 0.34 & 0.85 \\
\hline NBA & 14 & - & 0.18 & 0.05 & 0.44 & 0.90 \\
\hline NAA & 14 & + & 0.93 & 0.91 & 0.34 & 0.85 \\
\hline IUP & 14 & + & 0.85 & 0.81 & 3.35 & 0.85 \\
\hline VEP & 14 & + & 0.21 & 0.09 & 0.44 & 0.90 \\
\hline BCB & 14 & + & 0.72 & 0.65 & 0.37 & 0.86 \\
\hline INF & 14 & - & 0.58 & 0.48 & 0.39 & 0.87 \\
\hline RER & 14 & + & 0.87 & 0.83 & 0.34 & 0.85 \\
\hline CGR & 14 & + & 0.42 & 0.30 & 0.41 & 0.88 \\
\hline ZSC & 14 & + & 0.90 & 0.88 & 0.34 & 0.84 \\
\hline NPL & 14 & - & 0.86 & 0.82 & 0.35 & 0.85 \\
\hline SBA & 14 & + & 0.88 & 0.80 & 0.36 & 0.86 \\
\hline SLE & 14 & + & 0.38 & 0.26 & 0.41 & 0.88 \\
\hline TEST SCALE & & & & & 0.38 & 0.89 \\
\hline
\end{tabular}

Further, we use Kaiser-Meyer-Olkin (KMO) measure of sampling adequacy to check whether our data matrix is adequate for factor analysis as shown in Table 4.7. KMO measures sampling sufficiency for individual variables in the model and for the complete model. The statistics estimates the percentage of variance among the variables with higher proportions showing that your data is more suited to factor analysis. KMO measure of sampling adequacy is interpreted with values between zero and one. Small KMO measurement values less than 0.7 shows that in general variables are not mutually related to warrant a factor analysis (Kline 2004). We obtain 0.83 as our $\mathrm{KMO}$, which is just above 0.70 threshold, therefore we can perform a factor analysis using our data.

Table 4.7: Kaiser-Meyer-Olkin (KMO) Measure of Sampling Adequacy

\begin{tabular}{|l|l|}
\hline Variable & KMO \\
\hline NDA & 0.86 \\
\hline NBA & 0.64 \\
\hline NAA & 0.77 \\
\hline IUP & 0.69 \\
\hline VEP & 0.89 \\
\hline BCB & 0.85 \\
\hline INF & 0.67 \\
\hline RER & 0.73 \\
\hline CGW & 0.82 \\
\hline ZSC & 0.73 \\
\hline NPL & 0.88 \\
\hline SBA & 0.74 \\
\hline SLE & 0.77 \\
\hline OVERALL & 0.83 \\
\hline
\end{tabular}

\subsection{Confirmatory Factor Analysis (CFA)}

CFA is theory guided and therefore before we plan for our analysis we examine the association between the observed and unobserved variables. We used the already hypothesized model to measure a population covariance matrix and compare it with the observed covariance matrix. The numbers of factors and patterns of indicator-factor loadings are specified before CFA analysis is conducted. Figure 4.2 indicates SEM model used in CFA. Indicator variables are included in rectangular boxes while latent variables are shown in the oval shaped diagram. The circles represent the residual terms. Single headed arrows show our predicted relationships. To be able to determine if our model is well-identified one of the exogenous indicator from each latent variable is constrained to a unit (Kline, 2004). In our analysis, we place a factor loading of one on number of deposit accounts per 100,000 adults, inflation and banks' Z-score. Constraining an indicator variable permits us to exploit the relationship between the latent construct and the exogenous indicator variable in a non- recursive model to determine the variance of the latent variable.

CFA analyzes the factor loadings of each measurement variable on the expected latent variables and confirms if they are significantly associated (Thompson, 2004). After conducting CFA, we measure the structural relationship of the latent variables (inclusive finance, macroeconomic conditions and financial stability) using SEM. 


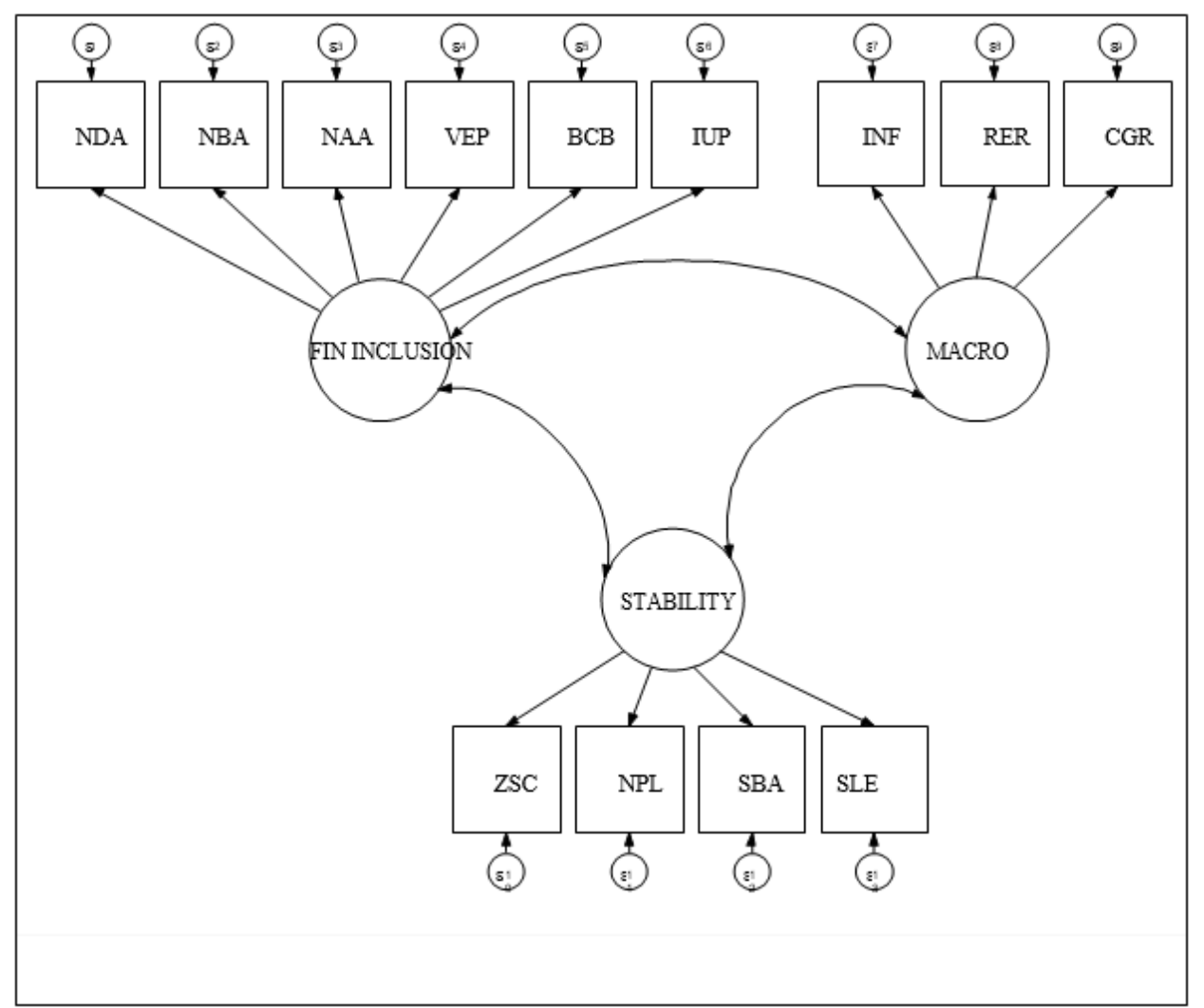

Note: Fin Inclusion is financial inclusion, Macro is macroeconomic conditions and Stability is financial stability.

Confirmatory factor analysis for inclusive finance as a latent construct and its measurement variables are displayed in Figure 4.3. The observed endogenous measurement variables included Number of deposit account per 100,000 adults, number of branches per 100,000 adults, number of ATMs per 100,000 adults, average growth rate in volume of electronic payments, borrowings from commercial banks per 1,000 adults and internet use penetration as percentage of the population. The unobserved variables include inclusive finance (latent construct) and the error terms.

Figure 4.3: CFA for Inclusive Finance and its Measurement Variables

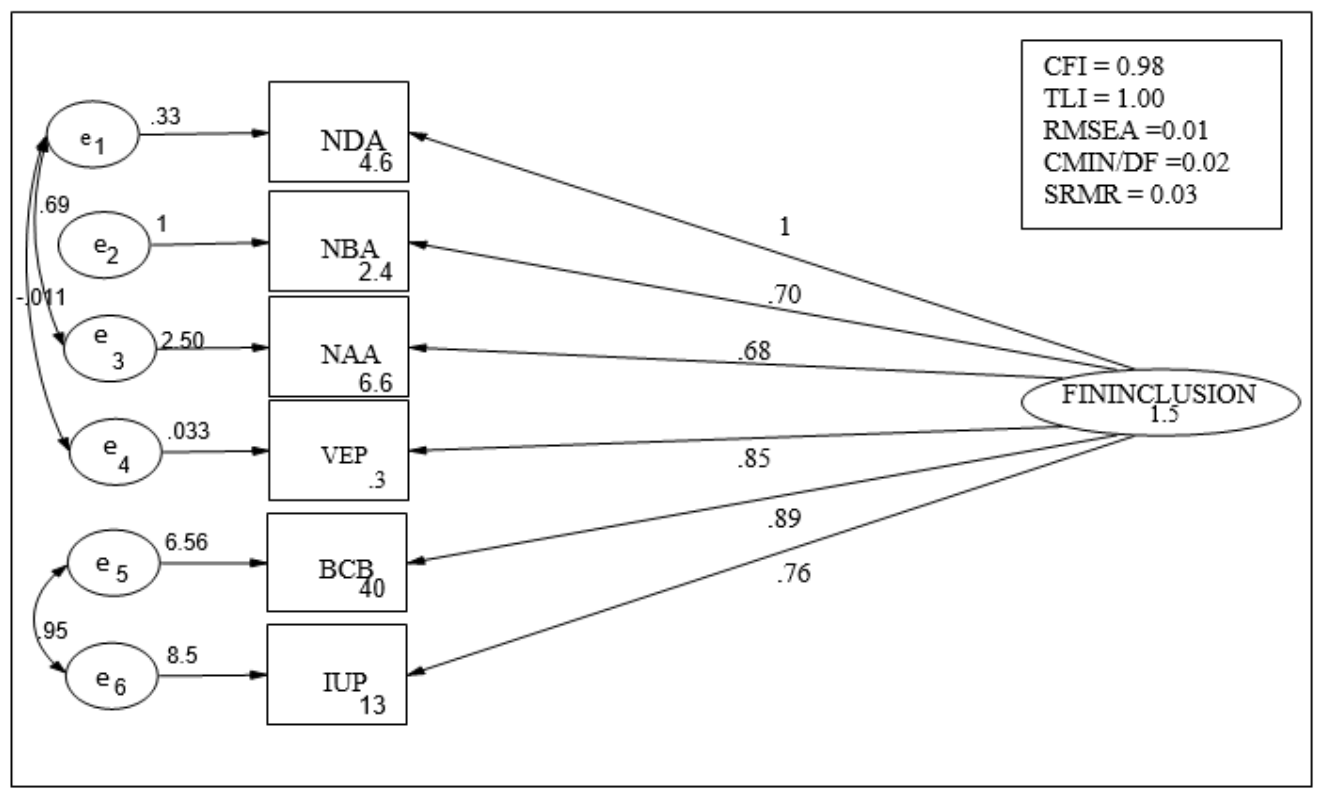

Note: CFI is Comparative fit index, TFI is Tucker Lewis Index, RMSEA is Root Mean Square Error of Approximation, CMIN/DF is Relative Chi-Square Value and SRMR is standardized root mean residual.

Estimation of regression weights showed that inclusive finance is significant in predicting all the measurement variables that represent it. The regression weight for inclusive finance in forecasting the number of 
deposit accounts per 100,000 adults (NDA) was constrained to 1.00 basing on a sound economic theory, which asserts that, inclusive finance expands when every individual at least owns a deposit account. This implies that when individuals open deposit accounts and utilize them then inclusive finance expands rapidly (Han and Melecky, 2013). The estimation weights for inclusive finance in forecasting the number of branches per 100,000 adults (NBA), number of ATMs per 100,000 (NAA), average growth rate in volume of electronic payments (VEP), borrowings in commercial banks per 1,000 adults (BCB) and internet use penetration as percentage of the population (IUP) were all statistically significant with p-value less than 0.05 . This shows that when there is increased access and usage of financial services through opening of bank branches, increasing number of ATMs and availing internet banking to the population, majority of the population will be included in the financial system. This is consistent with the findings of Cihak et al. (2016), Han and Melecky (2013) and Demirguc-Kunt et al., (2015).

The factor loadings that explain the effect of NBA, NAA, VEP, BCB and IUP on inclusive finance was 0.70 , $0.68,0.85,0.89$ and 0.76 respectively. Furthermore, estimates of the variance of the residual of measurement variables were found to be statistically significant. This implies that the spread for inclusive finance measurement variables was efficient and that all the measurable construct of inclusive finance had adequate factor loadings. The error terms of measurement variables were modified using the modification indices command to allow correlation between the residuals. This aimed at ensuring an ideal spread of variances and that all observable variables of inclusive finance had adequate factor loading. Further, modification indices assists in ensuring that the model has a good fit. The values in the boxes represent the variances of our measurement variables.

An assessment of the fit indices obtained from CFA was conducted to determine how the model fits the theoretical assertion. Chi-square test (CMIN/DF) is the most commonly used test of goodness of fit. We expect the Chi-square value not to be statistically significant for a model to be fit. However, in our estimated model the Chi square is significant at 0.02 , which suggest a poor model fit. Nevertheless, the chi-square test has a drawback that it admits all models when the sample size becomes adequately less (see Blunch, 2008). We therefore resort to other additional measures of model of fit. Comparative Fit Index (CFI) was introduced by Bentler, (1990) as a comparative measure which includes the values that lie between zero and one; a model is considered a good fit if $\mathrm{CFI} \geq 0.9$. Our model stated a CFI greater than 0.9 , which portrays a good fit. Tucker-Lewis (TLI) measure of goodness of fit also shows a value higher than its threshold of TLI $\geq 0.9$ as in CFI. Another important test is the Root Mean Square Error of Approximation (RMSEA), which offers a signal for a satisfactory fit founded on noncentral chi-square distribution. For a model to be fit the RMSEA $\leq 0.05$, the RMSEA in our model is less than 0.05 , which indicates a good fit. We also report the standardized root mean square residual, which considers a model to be fit if SRMR is below 0.05 as in RMSEA. Our model shows an SRMR less than 0.05 showing a good fit. This further confirmed that our model has observable measurement variables that efficiently describe the latent construct.CFA for macroeconomic conditions as a latent construct and its measurement variables was also conducted. Figure 4.4 shows the outcome of the analysis.

Figure 4.4: CFA for Macroeconomic Conditions and its Measurement Variables

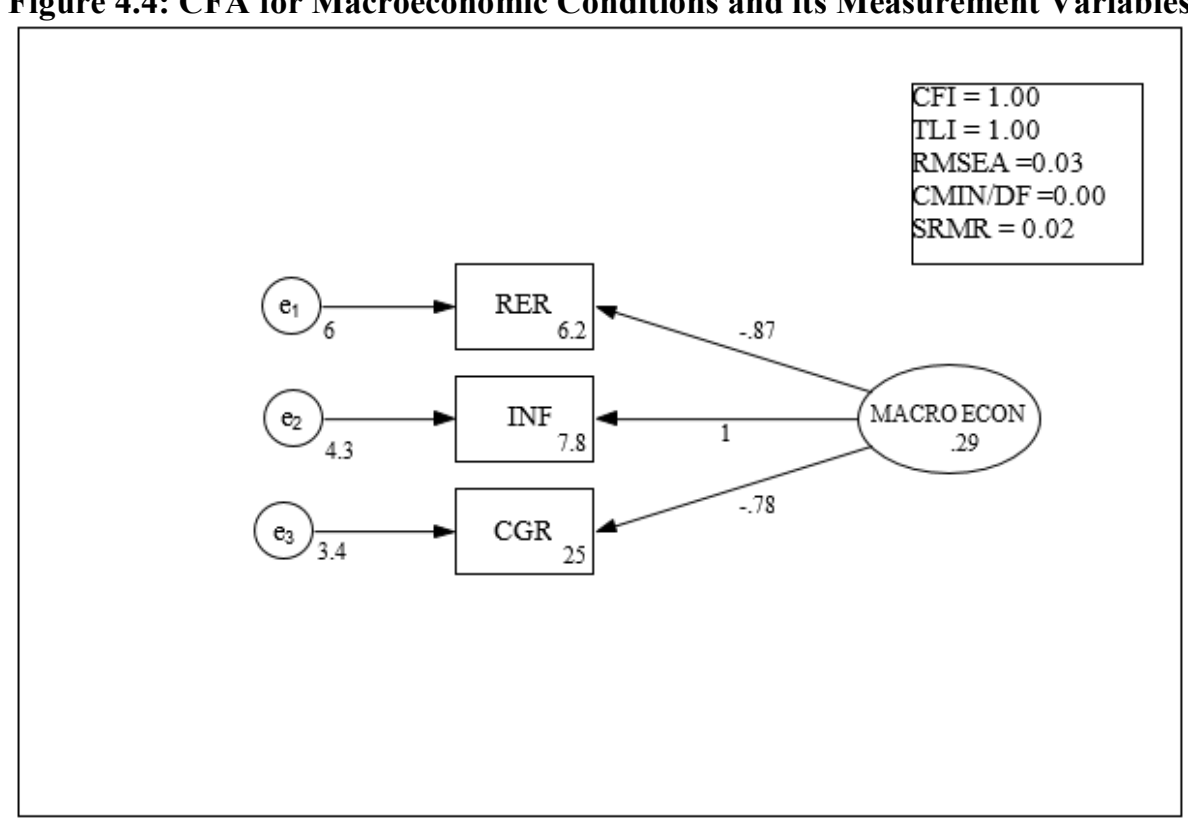

Note: CFI is Comparative fit index, TFI is Tucker Lewis Index, RMSEA is Root Mean Square Error of Approximation, CMIN/DF is Relative Chi-Square Value and SRMR is standardized root mean residual. 
The regression weight of macro economic conditions in forecasting inflation was set at 1.00 and for that reason it was not estimated. This was found on existing theoretical literature that macroeconomic instability increases as inflation increases (Duttagupta and Cashin, 2011). Therefore, when inflation increases by one unit macroeconomic instability also increases by one unit. Consequently, the estimation weight of macroeconomic condition in prediction of real interest rate was estimated at -0.87 . This implies that when macroeconomic condition becomes stable by one unit then real interest rate decreases by 0.87 units ceteris paribus (Von Hagen and Ho, 2007). Further, the regression weight of macroeconomic condition in forecasting credit growth rate was estimated at -0.78 . This implies that an increase in stability of macroeconomic condition by one unit leads to reduction in credit growth by 0.78 units other factor kept constant (Frankel and Saravelos, 2010). All the observable measurement variables were significant at $p$-value less than 0.05 . Thus, the path coefficient that explains the impact of real interest rate and credit growth rate on macroeconomic conditions is -0.3 and -0.7 respectively.

We further establish if the CFA indices fits the model in line with the hypothesized conjecture. Apart from the Chi-square test (CMIN/DF) all the other model fit statistics confirmed that macroeconomic conditions indices had a good fit in Figure 3.5. This shows that factor loadings for macroeconomic condition measurement variables loaded adequately on the latent construct (macroeconomic conditions).

CFA was further conducted on the four measurement variables of financial stability. The variables were allowed to correlate without restraints with each other but there was a parsimonious correlation between the residuals. The path diagram is presented in Figure 4.5.

Figure 4.5: CFA for Financial Stability and its Measurement Variables

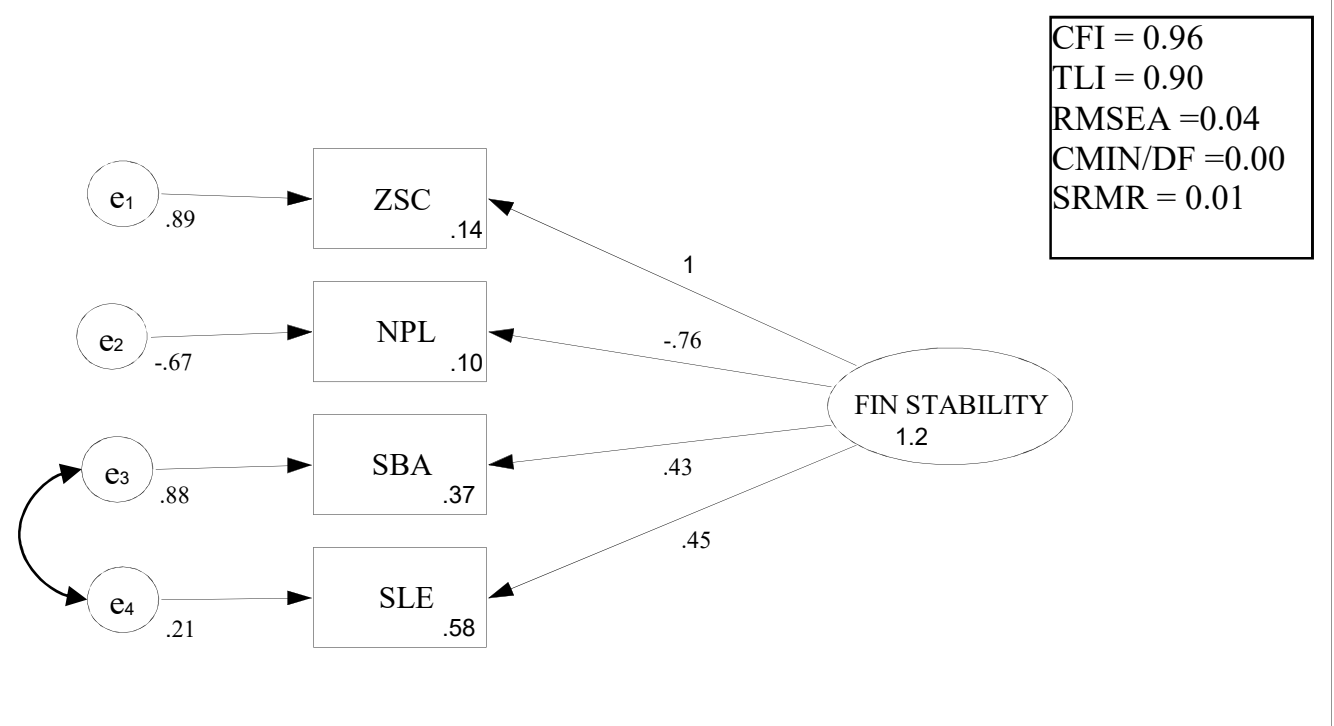

Note: CFI is Comparative fit index, TFI is Tucker Lewis Index, RMSEA is Root Mean Square Error of Approximation, CMIN/DF is Relative Chi-Square Value and SRMR is standardized root mean residual.

We constrained the Z-score variable with a factor loading of 1.00. This was based on the existing literature that a higher value of bank's Z-score implies that there is stability in the financial system (Li et al., 2017). The model hypothesized that the four measurement variables viz. Z-score (ZSC), ratio of non-performing loans (NPL), standard deviation of banks' deposit rate (SBA) and standard deviation of banks' lending rate (SLE) were correlated. The latent construct that represented all the measurement variables was financial stability. All the unconstrained paths for the measurement variables were statistically significant with $p$-value below 0.05 . The regression weight of financial stability in forecasting the ratio of non-performing loans had a coefficient of -0.76 . This means that financial stability improves by one unit when the ratio of non-performing loan reduces by 0.76 units (see Baum et al., 2005; Talavera et al., 2012). Consequently, the estimation weight of financial stability in predicting SBA and SLE was estimated at 0.43 and 0.45 respectively.

However, the deviation is not far from zero meaning that the financial system will be stable when the deviation is marginal but positive to allow banks earn interest from lending and at the same time encouraging individuals to deposit money in banks. The residual measurement variables were modified using the modification indices command to allow correlation between SBA and SLE error terms. This was intended to guarantee a perfect spread of the variances and to ensure that all observable variables of financial stability had higher factor loadings (Kline 2004).

A goodness-of-fit test was performed to confirm that our model has a good fit. The model fit statistics of all 
financial stability indices met the requisite threshold apart from the Chi-Square value. We therefore concluded that the factor loadings for the measurement variables could be relied on to measure the latent construct (financial stability).

\subsection{Structural Equation Model (SEM) Results}

In our SEM model, we estimated a non-recursive model of three latent constructs (inclusive finance, macroeconomics and financial stability). The unstandardized coefficient paths of: Number of deposit account per 100,000 adults (NDA), inflation (INF) and Z-score (ZSC) are constrained to one to address the identity problem. Therefore, there is no test of significance for these three paths. The constraint was based on sound economic theory (see Kline, 2004). We estimate our non-recursive unstandardized SEM model in three phases to see the covariance between inclusive finance and financial stability, macroeconomic conditions and financial stability and finally the covariance between inclusive finance and macroeconomic conditions. We further explain the channels through which inclusive finance and macroeconomic conditions affect stability of the financial sector.

The channel through which inclusive finance affects financial stability is presented in figure 4.6. The distribution channels that proxy access to financial services include number of deposit accounts, bank branches and ATM machines per 100,000 people. Another channel through which inclusive finance affects financial stability is usage of financial services. Usage is represented by growth rate in volume of electronic payments, borrowings from commercial banks per 1,000 adults and percentage of internet usage penetration.

Figure 4.6 shows a significantly positive covariance between inclusive finance and financial stability. Thus, inclusive finance has a significant causal effect with financial stability. A one percent increase in inclusive finance leads to a 0.65 percent increase in financial stability ceteris paribus. This finding is consistent with other empirical findings within our literature (Prasad, 2010; Morgan and Pointes, 2014; Cull et al., 2014; Han and Melecky, 2015; Amatus and Alireza, 2015; Cihak et al., 2016).

When uptake of financial services increases through access of bank services, banks are able to diversify their investments and expand their deposit base by including the low income earners whose spending patterns does not change significantly in case of a financial crisis. This enables banks to absorb shocks in case of a crisis (see Khan, 2011; Sahay et al., 2015). Usage of financial services through commercial banks borrowing, electronic payment and electronic commerce would ensure effective transmission of monetary policy. This would be significant in mitigating systemic risks if majority of the population is included in the financial system. Monetary policy targets consumption and spending patterns of the consumers and therefore any change in policy would indirectly affect usage of financial services (Morgan and Pointes, 2014; Amatus and Alireza, 2015). Consequently, when the population is able to access their deposits and borrow from banks they will be able to manage their consumption. Therefore, during economic downturns consumers are able to cushion themselves by utilizing their savings. This reduces the likelihood of panics that lead to bank runs and ensures that the consumption patterns of consumers do not change in the long run (Prasad, 2010; Sahay et al., 2015). However, it should be noted that customers can withdraw their savings at once and that savings decisions can be influenced by other factors.

A stable financial system may also enhance confidence and trust in financial systems, which in turn foster utilization of financial services. When there is a strong regulatory structure through robust institutions and wellcontrolled governance structures, financial stability will improve (Morgan and Pontines, 2014). It becomes easier for regulators to predict, mitigate and absorb financial shocks in a robust financial system. The government can also come up with better policies that allow access and usage of financial services in the long run. Inclusive finance will in turn decrease contagion effects linked with risks of financial exclusion. Accordingly, banks will find it easier to forecast their income hence encouraging them to diversify their investments (Sahay et al., 2015).

For post estimation statistics, we assess the goodness of fit of our SEM model to verify whether our model fits the hypothesized theory. Our model fit statistics shows mixed results as follows: CFI $=0.95$; TLI $=0.67$; RMSEA $=0.04 ; \mathrm{CUMIN} / \mathrm{DF}=0.00$ and $\mathrm{SRMR}=0.01$. Apart from relative Chi- square and Tucker-Lewis index all other model of fit statistics show that our model met the expected threshold of a good model. Figure 4.7 shows the causal link between macroeconomic conditions and financial stability. The channels through which macroeconomic variables affect financial stability includes: real interest rate, credit growth rate and inflation 
Figure 4.6: SEM Estimation Results for Inclusive Finance and Financial Stability

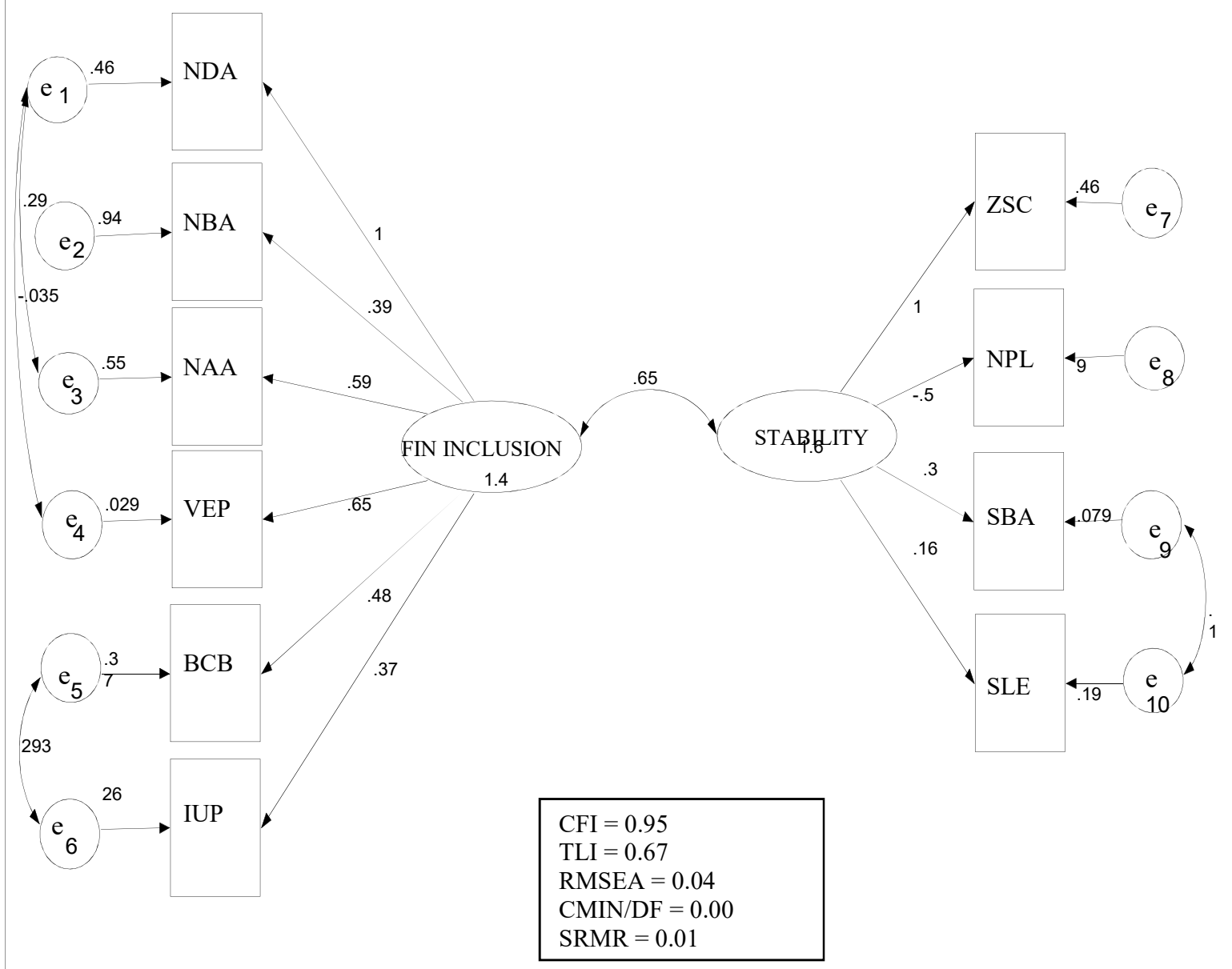

Note: Fin Inclusion is financial inclusion and Stability is financial stability.

Regarding the aspect of macroeconomic condition, the covariance between financial stability and macroeconomic condition is statistically significant with a negative coefficient. This implies that there is an inverse causal relationship between macroeconomic conditions and stability of the financial system. A one percent increase in severe macroeconomic conditions leads to a 0.53 percent reduction in financial stability. When there is high real interest rate, credit growth rate and inflation chances are high that credit risks will increase. Borrowers will be unable to pay loans leading to increased ratio of non-performing loans to total loans. Increased ratio of non-performing loans will threaten stability of the banking system and with its contagion effects spread to the entire financial system leading to a financial crisis (see Mohr and Wagner, 2013; Aikman, 2016). Therefore, stability of the financial system can be addressed through policies that reduce inflation and ensure price stability.

Further, adopting measures that control the continous increase in real interest rates and controlling the moral hazard effect associated with increased lending in risky ventures would also maintain the quality of lending. SEM results suggest that there are still high levels of inflation, real interest rates and credit growth in Kenya. The conjecture that adverse macroeconomic conditions leads to instability in the financial system is supported by Dhal et al., (2011), Cazla et al., (2004), Mohr and Wagner (2013) and Aikman (2016), who suggest that higher credit to GDP gap leads to instability in the financial system and recession in the long run. Further, these studies argue that real interest rates growth also affects the borrowing power of the population. Therefore, macroeconomic conditions may also have a significant effect on financial stability of a country. Our goodness of fit statistics shows mixed results as follows: $\mathrm{CFI}=0.90 ; \mathrm{TLI}=0.85 ; \mathrm{RMSEA}=0.02 ; \mathrm{CUMIN} / \mathrm{DF}=0.05$ and $\mathrm{SRMR}=0.04$. Apart from relative Chi- square, all other model of fit statistics show that our model met the expected threshold of a good model. 
Figure 4.7: SEM Estimation Results for Macroeconomic Conditions and Financial Stability

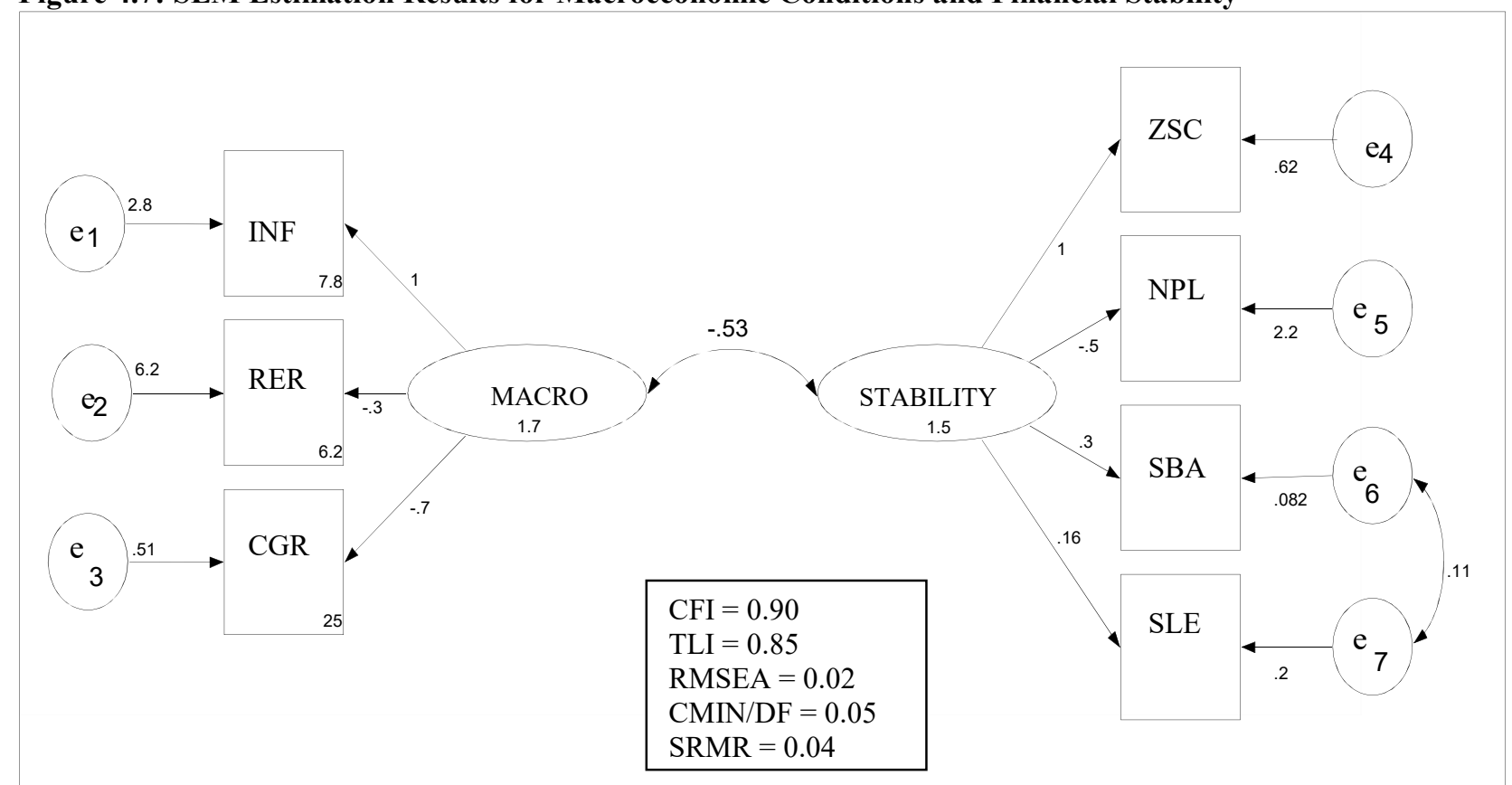

Note: MACRO is macroeconomic conditions and STABILITY is financial stability.

Figure 4.8 illustrates the channels through which macroeconomic conditions can affect the level of inclusive finance. Concerning the covariance between macroeconomic condition and inclusive finance, we find a significant inverse relationship between the two exogenous latent variables. This means that a one percent increase in severe macroeconomic conditions leads to a 0.47 percent reduction in inclusive finance.

The rise of lending rates and other indirect bank charges in Kenya discouraged many Kenyans from opening accounts in the past. Further, those who had accounts were not utilizing them (Upadhyaya and Johnson, 2015). Banks did not set their lending rates in relation to the CBK rate, but instead they used their own calculation of risks leading to many Kenyans opting to borrow money in the informal sector (Toroitich and Anyango, 2017). This led to the parliament passing a bill that sought to amend the Banking Act by placing restriction on the rate at which banks offer loans in 2016. This aimed at strengthening supervisory and regulatory framework to capture a huge percentage of the informal financial sector (CBK, 2016).

The SEM model also proposes some covariances between residuals of measurement variables to complement the relationship between latent constructs in ensuring stability of the financial system. Covariances are recommended to be implemented between the dimension of number of deposit accounts and ATMs per 100,000 people. This implies that as the number of deposit accounts increase, banks should open more ATM machines to allow customers access their savings conveniently. Further, the covariance between number of deposit accounts and the average growth rate in volume of electronic payment suggests that, as the number of deposit accounts increase customers tend to prefer using the electronic payment system to conduct their transactions.

The results of our model fit shows that our model is fit for SEM. It is as follows: $\mathrm{CFI}=0.95$; TLI $=0.90$; $\mathrm{RMSEA}=0.03 ; \mathrm{CUMIN} / \mathrm{DF}=0.45$ and $\mathrm{SRMR}=0.02$. All model of fit statistics show that our model met the expected threshold of a good model. 
Figure 4.8: SEM Estimation Results for Macroeconomic Conditions and Inclusive Finance

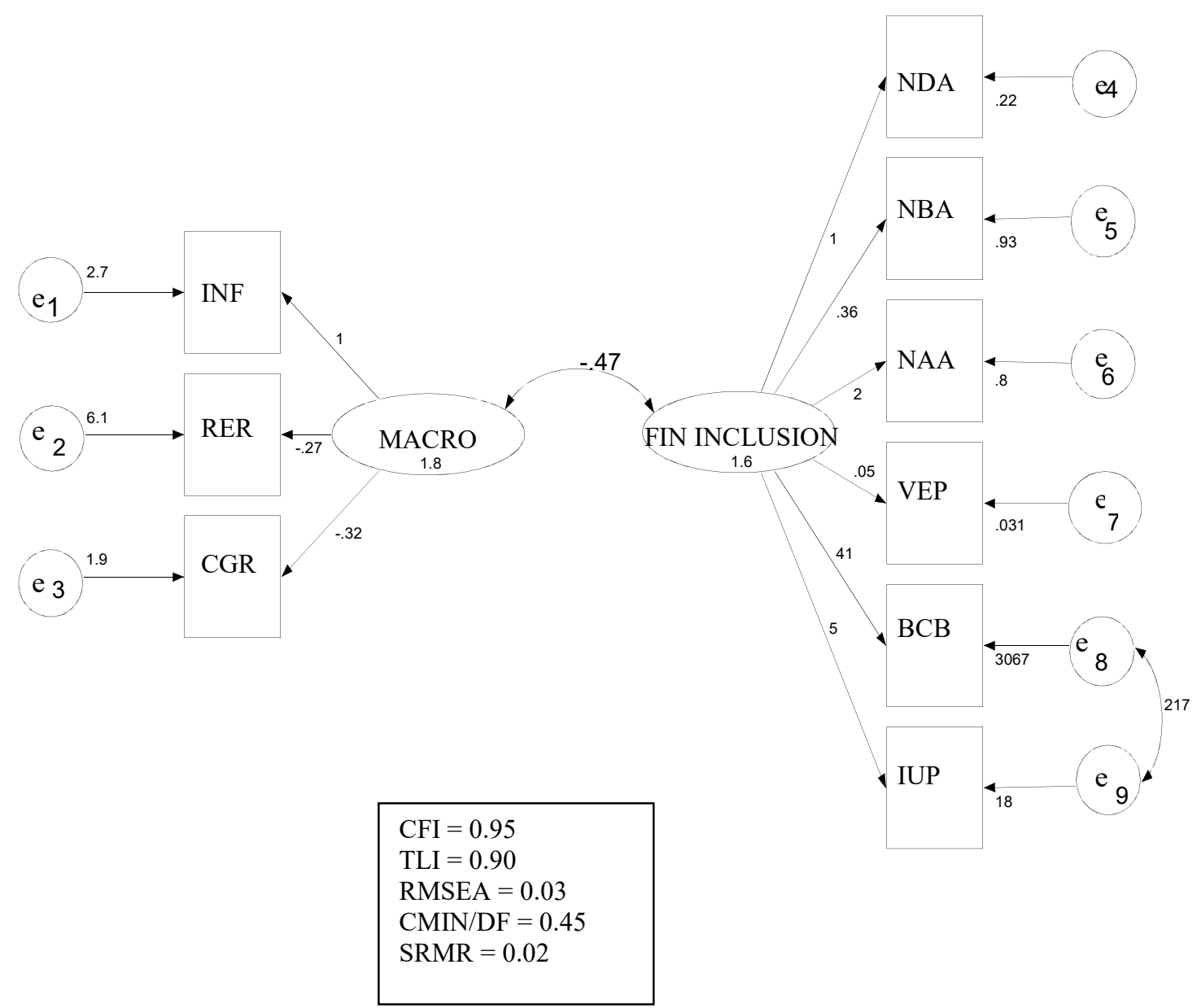

Note: MACRO is macroeconomic conditions and FIN INCLUSION is inclusive finance

Therefore, banks should consider improving their electronic payment systems as the number of depositors increase. Standard deviation of bank deposit rate and bank lending rate should also be evaluated together to reduce the lending and deposit rate spread. This will encourage individuals to deposit money in banks and to borrow money for investments leading to stability of the financial system and the economy as a whole. The correlation of these important factors could be seen as a new dimension to increase the uptake of financial services.

\section{Conclusion}

This study analyzes the impact of financial inclusion on financial stability in Kenya. A nonrecursive Structural Equation Model is developed with unstandardized variables that proxy financial access, usage and macroeconomic conditions as determinants of financial stability in Kenya. The major theories of financial inclusion and financial stability are also tested to determine whether they hold in the domestic financial market. We established that high levels of financial inclusion in terms of access and usage leads to improved financial stability in Kenya. However, it should also be noted that increased financial inclusion particularly related to wider borrowing by individuals, might raise the risk of severe events, unexpected losses in the financial system and eventually a bank crises. Additionally, financial stability also depends disparagingly on macroeconomic conditions. Our findings indicate that a more stable macroeconomic environment would certainly lead to a stable financial system in Kenya.

At the policy front, the government should enhance the transformation of the financial sector by introducing 
policies that will boost accessibility and usage of financial services. There is need for multiple government agencies to come up with financial sector strategies that would encourage uptake and usage of financial services. This can be done by easing bank regulations to encourage competition among commercial banks and creating a framework that ensures stability of the financial sector. Commercial banks should also play a role in financial inclusion by mobilizing deposits to expand their customer base. This can be done by opening more branches in the rural areas, increasing the number of ATM machines and agency banking in the country. Further, banks should improve digital finance and internet banking. They should also strengthen their electronic payment system to ensure easy transfer of funds at lower costs. These measures are critical in ensuring that financial services reach the unbanked population.

Commercial banks should also encourage usage of financial services by reducing bureaucracies involved in opening bank accounts and accessing loans. This can be done by utilizing existing innovative channels that can easily be accessed by majority of the customers. Such channels may include mobile and agency banking. Banks should also follow CBK regulations before advancing loans to their customers to reduce insolvency, credit and liquidity risks. Consequently, policymakers should come up with systems like macro-prudential framework for assessing risks and promoting sound macroeconomic policies. This will not only incorporate the regulation and supervision of financial institutions, but will also integrate macroeconomic considerations as well as risk exposure on increased bank concentration. Inter-linkages between different parts of the financial system that interact to ensure financial stability will also be considered.

\section{References}

Adasme, O., Majnoni, G. \& Uribe, M. (2006). Access and Risk: Friends or Foes? Lessons from Chile. World Bank Policy Research Working Paper, 4003.The World Bank, Washington DC, USA.

Aduda, J. \& Kalunda, E. (2012). Financial Inclusion and Financial Sector Stability with Reference to Kenya: A Review of Literature. Journal of Applied Finance \& Banking, 2(6), 95 -120.

Ahamed, M. M. \& Mallick, S. (2017). Is Financial Inclusion Good for Banking Stability? International Evidence. Journal of Economic Behavior and Organization. ISSN 0167-2681.

Aikman, D., Andreas, L., Nellie. L. \& Michele, M. (2016). Financial Vulnerabilities, Macroeconomics Dynamics, and Monetary Policy. Finance and Economics Discussion series 2016-055. Washington: Board of Governors of the Federal System.

Allen, F. (1990). The Market of Information and the Origin of Financial Intermediaries. Journal of Financial Intermediation, 1, 3-30.

Allen, F. \& Elena C. (2014). Mark-to-Market Accounting and Liquidity Pricing. Journal of Accounting and Economics, 45(2-3), 358-378.

Amanja, D. M. (2015). Financial Inclusion, regulation and Stability: Kenyan Experience and Perspective. United Nation Conference on Trade and Development. Multi-Year Expert Meeting on Trade, Services and Development. Geneva, 11-13 May 2015.

Amatus, H., \& Alireza, N. (2015). Financial Inclusion and Financial Stability in Sub-Saharan Africa (SSA). The International Journal of Social Science, 36(1).

Ardic, O., Mylenko, N. \& Saltane, V. (2011). Small and Medium Enterprises a Cross-Country Analysis with a New Data Set. The World Bank. Policy Research Working Paper 5538.

Bachas, P., Gertler, P., Higgins, S. \& Seira, E. (2016). Banking on Trust: How Debit Cards Help the Poor to Save More. Working Paper No. 34.

Baum, C., Caglyan, M. \& Ozkan, N. (2005). The Second Moments Matter: The Response of Bank Lending Behavior to Macroeconomic Uncertainties. Boston College, Working paper No. 521.

Beck, T., \& De la Torre, A. (2007). The Basic Analytics of Access to Financial Services. Journal of Financial Markets, Institutions \& Instruments, 16(2), 79-117.

Beck, T., Demirgüç-Kunt, A. \& Levine, R. (2010). Financial Institutions and Markets Across Countries and over Time: The Updated Financial Development and Structure Database. World Economic Review, 24(1), 77-92.

Blunch, N. J. (2008). Introduction to Structural Equation Modeling Using SPSS and AMOS. London: Sage Publications.

Bollen, K. (1989). Structural Equations with Latent Variables. New York: Wiley.

Cazla, A., Gartner, C. \& Souza, J. (2003). Modeling the Demand for Loans to the Private Sector in the Euro Area. Journal of Applied Economics, 35,107-117.

Central Bank of Kenya (2007-2017). Kenya Financial Sector Stability Report. Various Issues 2007-2016.

Central Bank of Kenya (1996-2016). Kenya Banking Supervision Annual Report. Various Issues 1996- 2016.

Cihak M. \& Melecky M. (2016). The Nexus of Financial Inclusion and Financial Stability: A Study of Possible Trade-offs and Synergies. Word Bank Policy Research Paper Series 111.

Cook, W. \& McKay, C. (2017). Banking in the M-PESA Age. Lessons from Kenya. Consultative Group to assist the Poor (CGAP). Working Paper No 13. 
Cull, R., Ehrbeck, T. \& Holle, N. (2014). Financial Inclusion and Development: Recent Impact Evidence. Focus Note 92, CGAP, Washington, DC.

Dhal, S., Kumar, P. \& Ansari, J. (2014). Financial Stability, Economic Growth, Inflation and Monetary Policy Linkages in India: An Empirical Reflection. Reserve Bank of India Occasional Papers. Vol. 32(3), Winter 2011.

Dattels, P., Miyajim, R. \& Puig, J. (2010). Can You Map Global Financial Stability? IMF Working Paper series 10/ 145 .

Demetriades, P. O. \& Siong, H. L. (2006). Financial, Institution and Economic Development. International Journal of Finance and Economics, 11(3), 245-260.

Demirguc-Kunt, A. Klapper, L. \& Singer, D. (2017). Financial Inclusion and Inclusive Growth: A Review of Recent Empirical Evidence. Policy Research Working Paper, WPS 8040. Washington, D.C. World Bank Group.

Demirguc-Kunt, A. Klapper, L. Singer D. \& Van Oudheusden, P. (2015). The Global Findex Database 2014: measuring financial inclusion around the world. Policy Research Working Papers Series 7255.The World Bank.

Demirguc-Kunt, A. Martinez, P. Maria, S. \& Tressel, T. (2015). The impact of the global financial crisis on firms' capital structure. Policy Research Working Paper Series 7522.The World Bank.

Demirguc-Kunt, A. \& Detragiache, E. (2000). Does Deposit Insurance Increase Banking System Stability? IMF Working Paper, WP/00/3.

De Nicolo, G. (2000). Size, Charter value and Risk in Banking: An International Perspective. International Finance Discussion Paper no. 689. Board of Governors of the Federal Reserve System.

Diamond, D. W. \& Philip H. D. (1983). Bank Runs, Deposit Insurance, and Liquidity. Journal of Political Economy 91(5), 401-419.

Financial Sector Deepening Kenya (2016). Household Survey. Annual Report

Financial Sector Deepening Kenya (2017). Creating Value through Financial Inclusion. FSD Strategy for the Period 2016-2020.

Financial Sector Deepening Kenya (2013). The 2013 FSD Annual report. Nairobi, Kenya

Financial Sector Deepening \& Central Bank of Kenya, (2016). FinAcess Geospatial Mapping. Harvard Dataverse, V1.

Fomum, A.T. \& Jesse, M. A. (2017). Exploring the Relationship between Financial Inclusion and Asset Accumulation. International Journal of Social Economics, 44(12), 2157-2172.

Frankel, J. \& Saravelos, G. (2010). Are Leading Indicators of Financial Crises Useful for Assessing Country Vulnerability? Evidence from the 2008-09 Global Crisis. NBER Working Paper No. 16047. National Bureau of Economic Research, Inc.

Ghosh, S. (2008). Financial Inclusion and Financial Fragility: An Empirical Note. MPRA Paper, No. 24252.

Gichuhi, M. M. (2013). The role of financial systems in the Kenyan economy Challenges and possible interventions (A theoretical review). Prime Journal of Business Administration and Management 3(10): 1197-1201.

Gudmundsson, R., Ngoka-Kisinguh, K. \& Odongo, M. T. (2013). The Role of Capital Requirements on Bank Competition and Stability: The Case of the Kenyan Banking Industry. Nairobi: Kenya Bankers Association.

Hall, K. (2008). The Importance of Financial Literacy. Address to the Conference on Deepening Financial Capacity in the Pacific Region. Sydney-25 August 2008.

Gujarati, D. N. (2003). Basic Econometrics. New York: McGraw Hill Book Co.

Hannig, A. \& Jansen, S. (2010). Financial Inclusion and Financial Stability: Current Policy Issues. Asian Development Bank, Working Paper Series, No. 259.

Han, R. \& Melecky, M. (2013). Financial Inclusion for Financial Stability: Access to bank deposits and the growth of deposits in the global financial crisis. Working Paper No. 6577.

Hardy, D. \& Pazarbasioglu, C. (1999). Determinants and Leading Indicators of Banking Crises: Further Evidence .IMF Staff Papers, 46(3), 247-258.

Hawkins, P. (2006). Financial Access and Financial Stability in Central Banks and the Challenge of Development. Bank for International Settlements, Basel, 65-79 Switzerland.

International Monetary Fund (2014). Deposit Insurance Database. International Monetary Fund, Washington.

Khan, H. R. (2011). Financial Inclusion and Financial Stability: Are They Two Sides of the Same Coin? Address given at BANCON 2011. Chennai, 4-6 November.

Kibua, T. N. (2007). Poverty Reduction through Enhanced Access to Financial Services: Case studies of Botswana, Kenya and Namibia. Institute of Policy Analysis and Research Occasional Paper No. 010/2007.

Kiviet, F. J. (2009). Strength and Weakness in Instruments in IV and GMM Estimation of Dynamic Panel Data Models. Department of Quantitative Economics, Amsterdam School of Economics, University of Amsterdam, Roetersstraat 11,1018 WB Amsterdam. 
Kline, R. B. (2004). Principles and Practice of Structural Equation Modeling. Second Edition: Guilford Publications.

Lehman, A. (2005). JMP for Basic Multivariate and Univariate Statistics: A Step by Step Guide. Cary, NC: SAS Press, pp. 123.ISBN 1-59047-576-3.

Li, X., Tripe, D. \& Malone, C. (2017). Measuring Bank Risk: An Exploration of Z-Score. Massey University, Palmerstone North, New Zealand.

Lopez, T. \& Winkler, A. (2017). The Challenge of Rural Financial Inclusion-Evidence from Micro-Finance. Journal of Applied Economics, 50(14), 35-57.

Lukonga, I. (2015). Islamic Finance, Consumer Protection, and Financial stability. IMF Working Paper.

Makina, D. (2017). Introduction to the Financial Services in Africa Special Issue. African journal of Economic and Management Studies, 8(1), 2-7.

Mare, D. S., Moreira, F. \& Rossi, R. (2015). Nonstationary Z-Score Measure. Working Paper 351.

Marconi, R. \& Mosley, P. (2006). Bolivia During the Global crisis 1998-2004. Towards a Macroeconomics of Microfinance. Journal of International Development, 18, 237-261.

Mehrotra, N. A. \& Yetman, J. (2015). Financial Inclusion and Optimal Monetary Policy. BIS Working Paper No. 476.

Musinga, M. \& Ongayo, M. (2002). An Evaluation of Micro-Finance Programs in Kenya. Steering Committee for the Evaluation of the Netherlands Co-Financing Program. New York. UN Development Program.

Morgan, P. \& Pointes, V. (2014). Financial Stability and Financial Inclusion. ADBI Working Paper 488. Tokyo: Asian Development Bank Institute. www.

Mohr, B. \& Wagner, H. (2013). A Structural Approach to Financial Stability: On the Role of Regulatory Governance. Journal of Governance and Regulation, 2(1), 2013.

Mwega, F. M. (2014). Financial Regulation in Kenya: Balancing Inclusive Growth with Financial Stability. Overseas Development Institute, Working paper 407, 27-36.

Nunnally, J. C. \& Bernstein, I. H. (1994). Psychometric theory (3rd Ed.) New York: McGraw-Hill. 1999, 17, 275 280.

Operana, B. (2016). Financial Inclusion and Financial Stability in the Philippines. Published Masters Dissertation. Graduate School of Public Policy (GraSPP). The University of Tokyo.

Patten, R. H., Rosengard, J. K. \& Johnson, D. E. (2001). Microfinance Success amidst Macro Economic Failure: The Experience of Bank Rakyat Indonesia during the East Asian Crisis. World Development, 29(6), 10571069.

Pearl, J. (2000). Causality: Models, Reasoning and Inference: Cambridge University Press.

Powell, D. \& Schafer, W. (2001). The Robustness of the Likelihood Ratio Chi-Square Test for Structural Equation Models: A Meta-Analysis. Journal of Educational and Behavioural Statistics, 26(1), 105-132.

Prasad, E. (2010). After the Fall: Central Banking Challenges in the Aftermath of the Crisis. Journal of Finance and Development, 47(2), 22-25.

Rabe-Hesketh, S., Skrondal, A. \& Pickles, A. (2004). Generalized Multilevel Structural Equation Modeling. Psychometrika, 69(2), 167-190.

Rhyne, E. (2001). Mainstreaming Microfinance: how Lending to the Poor Began, Grew and Came of Age in Bolivia, West Hartford CT: Kumarian Press.

Roa, M. J. (2015). Financial Inclusion in Latin America and the Caribbean: Access, Usage and Quality. Research Papers 19, CEMLA.

Sahay, R., Cihak, M., N'diaye, P., Brajas, A., Mitra, S., Kyobe, A., Mooi, N. \&Yousefi, S. R. (2015). Financial Inclusion: Can it Meet Multiple Macroeconomic Goals? IMF Discussion Note. SDN/15/17. G10.

Sarma, M. \& Pais, J. (2011). Financial Inclusion and Development. Journal of International Development, 23, 613-625.

Singh, N. (2017). Financial Inclusion: Concepts, Issues and Policies for India. International Growth Centre.1$35406-I N C-1$.

Soskic, D. (2011). Financial Literacy and Financial Stability. Key Note Speech at the Bank of Albania Ninth International Conference Building, 'Our Future through Financial Literacy, Tirana, 15 September.

Staschen, S. \& Gidvani, L. (2014). Financial Inclusion and the Linkages to Financial Stability, Integrity and Consumer Protection: Insight from Russia Experience. Discussing the Linkages among I_SIP objectives in Russia. Russian Microfinance Centre, Bankable Frontier Associates.

Swamy, V. (2014). Financial Inclusion, Gender Dimension, and Economic Impact on Poor Households. World Development, 56, 115.

Talavera, O., Tsapin, A. \& Zholud, O. (2012). Macroeconomic Uncertainty and Bank Lending: the case of Ukraine. Economic System, 36(2), 279-293.

Tomarken, A. J. \& Waller, N. G. (2005). Structural Equation Modelling: Strengths, limitations and Misconceptions. Journal of Annual Review of Clinical Psychology, 5, 31-65. 
Toroitich, C. J. \& Anyango, W. (2017). Effects of Interest Rate Stability on Kenya's Economic Performance. The Strategic Journal of Business and Change Management, 56, 2312-9492.

Triki, T. \& Faye, I. (2013). Financial Inclusion in Africa. Africa Development Bank Group Publication.

Upadhyaya R \& Johnson S. (2015). Evolution of Kenya's Banking Sector 2000-2012. In A Heyer \& M. King (Eds.). In: The Kenyan Financial Transformation. Nairobi: FSD Nairobi 2015.

Von Hagen, J. \& Ho, T. K. (2007). Money Market Pressure and the Determinants of Banking Crises. Journal of Money, Credit and Banking, 39(5), 1037-1066.

World Bank (2011). Finance for All? Policies and Pitfalls in Expanding Access, Washington, DC. http//:www.documents.worldbank.org/curated/en.

World Bank (2012). Global Financial Development Report 2013: Rethinking the Role of the State in Finance. Washington DC; World Bank.

Yaffee, R. (2003). A Primer for Panel Data Analysis. Connect Information Technology at NYU, 1-11.

Zollmann, J. (2014). Kenya Financial Diaries: Shilingi Kwa Shilingi. The Financial Lives of the Poor, Nairobi: FSD Kenya.

Zollmann, J. and Collins, D. (2010). Financial Capability and the Poor. Are we missing the market? FSD insights 02, FSD Kenya, Nairobi. 